\title{
Partnership for accelerated insertion of new technology: case study for thermal spray technology
}

\author{
Sanjay Sampath ${ }^{1 *}$, Gopal Dwivedi ${ }^{1}$, Alfredo Valarezo ${ }^{2}$ and Brian Choi ${ }^{1,3}$
}

\author{
* Correspondence: sanjay.sampath@ \\ stonybrook.edu \\ ${ }^{1}$ Center for Thermal Spray Research, \\ Stony Brook University, Stony Brook, \\ NY 11794-2275, USA \\ Full list of author information is \\ available at the end of the article
}

\begin{abstract}
Introduction: Materials and manufacturing innovation in complex engineering systems such as those in aerospace, energy, heavy machinery is extremely challenging as they typically involve lengthy and costly development cycles and generally follow stringent guidelines and defined road maps. Incorporating academic science and disruptive advances into this product development cycle is challenging. Effective partnerships via integrated academic-industry study groups and joint value proposition of scientific advances and models, can accelerate insertion of new knowledge/technologies in this class of materials and manufacturing ecosystems.

Case Description: This paper describes such a partnership and integration framework through exemplary case studies in thermal spray materials processing. Thermal spray is a platform materials manufacturing technology enabling deposition of advanced coatings for wide range of materials applications in aerospace, energy, heavy machinery, electronics and biomedical devices. It is a complex process involving many facets of engineering sciences including thermo-fluids, heat transfer, materials science and mechanics, incorporating non-equilibrium phenomena and multi-scale structure/behavior. The required breadth and depth of process and materials knowledge for advancing the technology is very significant, resulting in lengthy, trial and error based developments.

Specific case studies illustrate knowledge advancement through science and models, development of measurement tools and simulations, along with industrial demonstration studies, addressing the utility in the manufacturing enterprise. Together, they represent a framework for establishing integrated computational and experimental materials engineering concepts and serve as a model ecosystem for accelerating innovation in complex industrial manufacturing processes.
\end{abstract}

Keywords: Thermal spray, Coatings, Process modeling, Residual stresses, Knowledge transfer partnership, ICME

\section{Part 1: Materials and manufacturing innovation challenges in engineering systems}

Innovation is driven by a desire to create new markets and applications or to use new technology to produce better products at lower cost. The last few decades have demonstrated the power of accelerated innovation in fueling rapid-growth and enhancing the quality of life. Academia and small business have been at the forefront of

\section{黛 Springer}

(C) 2013 Sampath et al.; licensee Springer. This is an Open Access article distributed under the terms of the Creative Commons Attribution License (http://creativecommons.org/licenses/by/2.0), which permits unrestricted use, distribution, and reproduction in any medium, provided the original work is properly cited. 
innovation in modern times contributing to technology growth. Noteworthy are accomplishments in software, electronics and services where technological growth can sometimes be measured in weeks and months rather than years and decades. In many of these areas, the transition of concepts to market usually occurs over a relatively short time-span aided by substantial investments in venture capital. By contrast, innovations in engineering systems, materials, and manufacturing, although numerous, are defined by lengthy implementation and slow transitions from research to manufacturing integration. Government investments and regulatory policy have played pivotal role in minimizing risk. Along the way, many technologies, particularly those developed in academia and small businesses have fallen wayside or into the so called 'technology valley of death'. This has to a large extent stymied innovation and technology transfer.

In materials and manufacturing enterprises and complex engineering systems, product development is often a linear process where a perceived market-need drives the development of a product. The innovation flow generally follows a business-to-business transition path with only indirect relevance of the technology advances to consumers. System designers work to create the product and determine materials and engineering requirements, which in many cases are met with adaptations of existing technology or through appropriate enhancements. In selected cases, identified requirements of new manufacturing technology/material drive the innovation process within the supply chain. Such a "top down" approach typically has a high chance of success but the innovation is largely incremental and subject to inertial ambivalence. Furthermore, often a disconnect exists among the designers, product planners and technology developers leading to lengthy development cycles. On the other hand, a "bottom up" approach where new technology drives product development often fails due to either the well-known "Valley of Death" between applied research and actual adaptation of technology [1] or reluctance of system producers OEM's to quickly adapt new technology due to associated risks and costs. This is particularly an issue for academic research and small business innovations which are generally supported by government programs are often limited to low technology and manufacturing readiness levels. Establishing communication among the key stake holders is often challenging and in many instances contributes to the demise of promising knowledge and technologies. Figure 1 illustratively captures the two innovation pathways in product development and technology adaptation specifically in materials and manufacturing of complex engineering systems. The top figure is system driven and generally follows an established road map. The bottom-up approach can arise through serendipitous discovery or through fundamental knowledge. Latter needs to be integrated within the system road map for successful transition.

Clearly, effective communication among the relevant players and improved organization of the innovation, data and advanced modeling capabilities is necessary to ensure that promising technologies are adapted in the market place. Secondly, enhanced bridging is required between bench level inventions (new materials, models, diagnostics, sensors etc.) to industrial implementation (e.g. modified compositions and manufacturing advances). Thus, in order to facilitate rapid incorporation of new technology, materials, and processes, engineers as well as designers must be given more degrees of freedom to perpetuate innovation which is only possible through the integration of all players: OEM's, equipment manufacturers, component and material suppliers. 


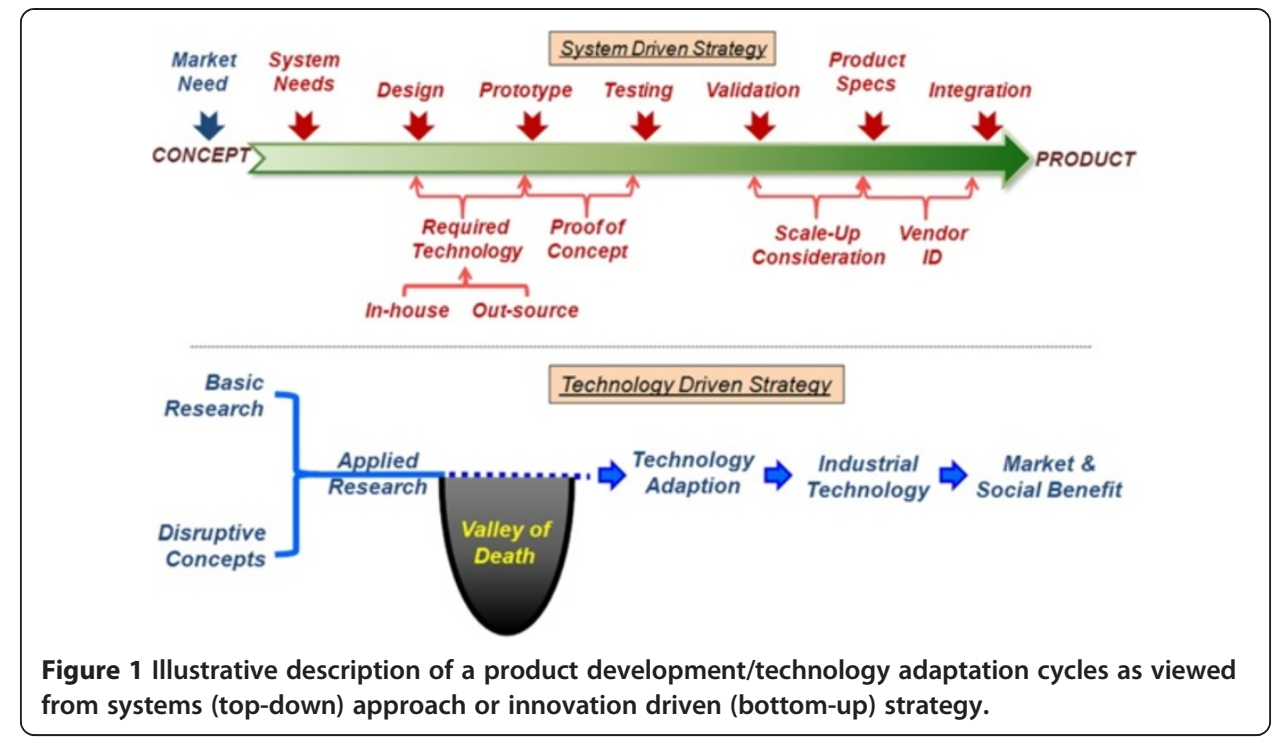

Of particular importance is the effectiveness of academic-industrial interactions in applied research and technologies that are important, yet perceived as traditional areas of engineering. For instance, academia has been in the forefront with respect to advances in materials theory, characterization and models as well as tools for process and manufacturing development. On the other hand, industry, driven by cost, risk, and reliability issues has set-up stringent requirements and specifications for any new materials or process integration. To ensure that promising new technologies are adapted in the market-place both academia and industry must appreciate their respective roles and constraints associated with the transitioning of enhanced knowledge and technologies. Academia and small businesses needs to consider system level issues within the context of the research and development exercise, particularly when developing and applying models and experiments, while industry, in addition to educating academia on system level issues also consider science driven-technology development which accelerates integration of innovation within the system.

\section{Partnership for accelerated insertion of new technology (PAINT)}

One approach to addressing the challenges outlined in the earlier section and to accelerate implementation of materials and manufacturing innovation is effective and continuous engagement of all the stakeholders (system designers, developers, academics and manufacturers) early on in the product development lifecycle. We outline here one such academically-centered concept acronym PAINT. PAINT is a framework to bring together academia and industry in a pre-competitive setting to shrink the product development and innovation life cycles in engineering materials and systems by engaging top-down system definitions, with bottom-up knowledge and innovation. Unlike traditional bilateral programs between academia and a specific industry, PAINT seeks involvement of all parties in the research, development, supply chain, manufacturing, and education cycle, enabling a concerted, integrated effort in topical areas of interest. PAINT as a platform concept, potentially is also a mechanism to promote flexibility and agility in response to changing technological landscapes. The key components of PAINT is system driven research, focused knowledge 
transfer, targeted human resource development, sustained workforce education in emerging technologies, and outreach.

PAINT strategy benefits both industry and the scientific community in the following ways:

- Rapidly examine value proposition of new technologies, models and material insertion across the supply chain to demonstrate business benefits

- Enable identification of critical implementation issues and adaptation requirements for innovative new ideas and products

- Provide a unified platform for standardized evaluation of available technologies, methods and models and pathways for innovation

- Provide a framework to stake holders (investors, innovators, practitioners and educators) for critical assessment of the technology portfolio

- Establish knowledge-technology connections

- Robust science driven technology development with far reaching implications

- Introduce new technologies, scientific methodologies and advanced databases

- Retool the present workforce and develop future engineers through sustained educational outreach

The concept of PAINT is demonstrated here for the field of thermal spray technology, an exemplary advanced materials manufacturing enterprise with a broad array of engineering applications. PAINT is a recent outgrowth of an established academic research center and an existing industry-university alliance at Stony Brook University. PAINT was formulated in recent years to ensure effective transition of fundamental science in to engineering practice. A critical aspect of the PAINT efforts was to demonstrate value propositions of scientific advances to industrial practice thereby enabling their accelerated incorporation into the manufacturing enterprise. PAINT to a large extent was made possible through the existence of thriving academic-industrial consortia. A time line for the PAINT evolution is presented in the following section and demonstrated in later part of the paper through illustrative case studies of PAINT implementation. Prior to the introduction of case studies, background of the thermal spray technology platform, innovations in materials and processes, along with the establishment of the industrial partnership is briefly described. Following the presentations of PAINT case studies, future directions and strategies are described from and integration and ICME perspective and finally closing out the paper with remarks that may enable other materials and manufacturing platforms to engage in similar PAINT type programs.

\section{Part 2. Thermal spray technology: a model for PAINT in practice}

Thermal spray (TS) is a directed melt spray deposition process that has emerged as a versatile technology for materials synthesis and fabrication of protective and multilayered coatings. TS-deposited layers are crucial to the economic and safe operation of a range of engineering systems, often under extreme conditions [2]. Thermal spray, a platform technology, is a $\$ 6$ Billion worldwide industry and impacts a diverse range of engineering industries. Applications range from ceramic thermal barrier coatings (TBCs) for enhanced efficiency in propulsion and energy turbines; environmentally 
benign manufacturing of wear resistant coatings; (e.g. replacement of electroplated hard chrome), friction reducing coatings in a range for sliding surfaces; active and passive corrosion control coatings; novel biocompatible implant coatings; surface engineering solutions to reduce material consumption in electronics manufacturing; etc. Figure 2 shows examples of thermal spray applications.

One advantage of the process is its flexibility and cost effectiveness; this enables the rapid introduction of new, unique or experimental materials into high performance applications. The process is scalable and reconfigurable and thus adapts to changing market need. Recent innovations have allowed the consideration of TS applicability well beyond 'traditional' overcoats into creation of functional surfaces, systems with complex chemistries, and patterned mesoscale devices [3-5].

Despite the virtues and unique advantages of thermal spray processing, its implementation into advanced systems and manufacturing processes have been slow, implementation times ranging from years to decades. Numerous innovations in process and materials technology have been stifled due to lack of adaptation. To a large extent, this may be attributed to the complex process-materials interactions, lack of fundamental knowledge and associated risk factors involved in implementation. However, the situation is changing; there is recognition among the engineering community that future materials systems will be multifunctional, requiring novel multilayer integration concepts in components. Increased confidence in thermal spray materials and processes has been demonstrated through successful utilization in critical applications such as hard chrome replacement in aircraft landing gear and as chamber coatings in semiconductor manufacturing. Coupled with this recognition, the technology has also benefited from significant investments into advancing the foundational science as well as a "coming together" of the key players to integrate into applications. Two examples of such integrated research and development activities in US academia are described below:

\section{Enhancements in scientific understanding}

Thermal spray is a highly complex materials' engineering process involving two back-toback phase changes each occurring in micro-second time scales. Furthermore, these non-equilibrium events are associated with strong thermal gradients. Spray particles of varying sizes are dynamically heated and melted (in some cases not melted but softened) in thermal plasmas and combustion heat sources following which rapid solidification occurs over a range of cooling rates. The resultant material characteristics can be variegated involving metastable phase formation, multi-scale in microstructural character and

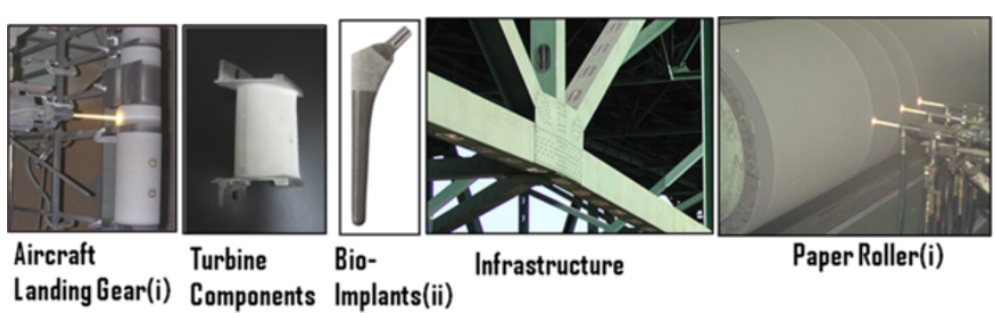

Figure 2 Examples of thermal spray applications in engineering systems. Ref. (i) Adolphson PY, Salemyr MOF, Skoldenberg OG, Boden HSG (2009) Large femoral bone loss after hip revision using the uncemented proximally porous-coated Bi-Metric prosthesis. Acta Orthop 80:14-19. (ii) Vuoristo PMJ (2007) High velocity sprays boost hard metal industrial coatings. Metal Powder Report 62:22-29. 
comprising of hierarchical grain sizes along with a myriad array of interphases and interfaces. Figure 3 broadly captures the various phenomena occurring in these processes and their impact of materials properties. These attributes are rich for interdisciplinary scientific studies but also can be an enigma from the point of view of translating scientific knowledge to industrial practice. Traditional aspects of equilibrium thermodynamics and phase diagrams are generally non-applicable in these kinetically driven processes resulting in a "Edisonian" approach to process optimization and materials design. Nevertheless, much progress has been achieved in recent years particularly in the arena of scientific advancements.

Around the world, many academic groups have been engaged in thermal spray scientific research [6-24]. Historically, many of the groups have specific research focus, broadly classified into following fields: process dynamics, instrumentation and diagnostics, process modeling, materials characterization and application engineering. In recent years, the interest in nano-materials has facilitated non-traditional academic groups from adopting thermal sprays as a method of choice for synthesis and characterization of range of classes of nano-materials [25-30]. In this endeavor many nuances of thermal spray processes have emerged including the use of suspensions and solution chemistry as precursors for non-equilibrium treatment. The field is rich in diversity in terms of materials, devices, diagnostics and materials synthesis. However, this flexibility has also been a challenge as the multitude of variables, many of which are interacting, results in inconsistent and non-reproducible results. Small variations in feedstock materials or processes can impart dramatic differences in material character, properties and even observed phenomena. Overwhelming amounts of process nuances and material data have left industrial adoption of innovation ineffective. It has become clear that the path forward involved not only interdisciplinary analysis but also an integration of the various operating phenomena to provide a holistic and comprehensive understanding of the processes and materials. In recent years, select research groups around the world have attempted such integrated methodology.

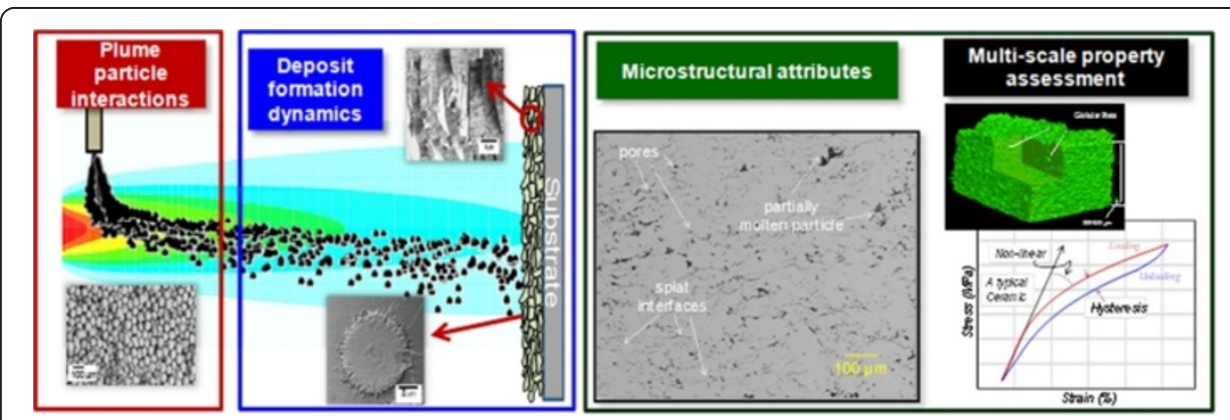

Figure 3 Phenomenological breakdown of research components addressing the multidisciplinary elements of thermal spray processes. Left: the first particle-plume interaction governing the primary melting extent and kinetic energy of particles. Center: The key attributes involved in the layer by layer formation of coatings. The particle impact and stacking plays an important role on the coating properties. Right: various characteristics and properties of spray formed coatings. The microstructure exhibits many defects associated with droplet based assemblage. A computed tomography of a three dimensional coating microstructure is shown on the top right. The defected structure introduces non-linear stress strain behavior with hysteresis associated with interfacial sliding among the splats. Integration among the three represented blocks is of critical importance and subject of past and on-going studies. 
Because materials science is at the core for understanding thermal spray, the US National Science Foundation established a Materials Research Science and Engineering Center at Stony Brook University in 1996 based on an interdisciplinary group of researchers in partnership with other academic, national laboratory, industrial and international partners. The goal was to achieve fundamental insights into TS processes and their implications for the synthesis, properties and performance of engineered surfaces all conducted in an integrated framework. This program was renewed in 2000, with expanded efforts in research and educational/industrial outreach and following a successful 11 year life cycle, has been established as a self-sustaining industry-university partnership. Center for Thermal Spray Research (CTSR) has established liaisons among US/foreign universities, national labs, and industry for enhanced graduate/undergraduate training.

Key developments in the field and briefly discussed within the context of the various phenomena described in Figure 3:

1) Particle flame interactions assessed through real time $3 D$ multi-instrument process diagnostics coupled with 3D process modeling [24,31-36]. These advancements provided mechanistic understanding of the complex phenomena occurred during thermal spray, especially pertaining to different types of materials and their feedstock character (size and morphology of particles). For instance, diagnostics when coupled with models describe inflight metal oxidation, evaporation in low conductivity oxides and decomposition processes of thermally sensitive materials. Real time diagnostics also allowed for advanced mapping strategies including identification of robust thermo-physical parameters for integrated description of the particle thermal and kinetic parameters which ultimately affect the deposition process [37]. New approaches to construct these maps using nondimensional parameters have allowed cross-comparison across materials and processes [38]. These particle status maps can be combined with property measurements providing an integrated linkage from feedstock materials to coating design factors.

2) Thermal spray deposit formation dynamics is highly complex phenomena involving droplet impact, spreading, rapid solidification and layered assembly of different sized impact droplets (splats). The characteristics of splat formation are governed not only by the aforementioned particle states but also substrate condition and spray environment. In most cases, each splat forms independently but coupling within the assemblage of thousands of splats, is also affected by the process conditions. Much progress has been achieved in our understanding of both individual droplet formation as well as coatings [18,39-44]. Systematic experiments have been carried out particularly within academia coupled with highly sophisticated spreading and solidification models [34,45]. The models provide insights into the experimental observation while simultaneously offering guidance in terms of materials and process selection.

3) Advanced multi-scale characterization of the 3D microstructure using sophisticated tools such as small angle neutron scattering and $\mathrm{x}$-ray microtomography has provided a basis for quantitative delineation of the defect architecture include content and type of the defects [46,47]. For instance scattering techniques go 
beyond traditional metallographic investigation as they provide volumetric data in $3 \mathrm{D}$ along with quantitative description of the defects (e.g. pore size, shape and anisotropy). These investigations have been coupled successfully with microstructure models (e.g. object oriented finite element analysis-OOF) resulting in establishment of microstructure-property relationships $[48,49]$.

4) New techniques have been developed for mechanical, thermal and functional characterization of these anisotropic layered coatings including the ability to extract design relevant properties [50-56]. Of particular importance is the knowledge of stress evolution and residual stresses associated with coating formation and cooling. Breakthrough advances in stress description using beam curvature; neutron and $\mathrm{x}$ ray based probing have allowed quantitative description of the stress-fields based on materials and process conditions. Here again, modeling has provided insights into the underlying mechanisms and enabled opportunities to guide in the development of process/material parameters.

These items provide only a snap-shot of the science and technology developments within the field of thermal spray. However, realization of these advancements in manufacturing requires not only integration of the knowledge-technology connections but also demonstration of their benefits in a realistic industrial environment. This is discussed further in the subsequent sections.

\section{Knowledge transfer partnership: Industrial Consortium for Thermal Spray Technology}

Historically, given the nature of thermal spray technology, academic researchers around the world have had a very strong relationship with industry. These interactions have largely been binary. In other words, industry presents a problem or an opportunity and allowing academic focus to determine the solution. Integrated interdisciplinary program such as the National Science Foundation Center was a game changer, in the sense, that activities not only focused on the underlying material science of non-equilibrium derived structures but also conducted them in the context of industrially relevant systems and processes. However, the connectivity to industrial applications was still limited due to absence of system level thinking of the scientific enhancements. To foster this interaction, along with continued support from the National Science Foundation, researchers at Stony Brook in concert with its industrial partners established a research and knowledge transfer partnership with a diversity of thermal spray related industries under the framework of the Consortium for Thermal Spray Technology. This initiative was in response to the recognition that the diversity of TS applications worldwide, nominally an advantage, was resulting in application-specific and thus disconnected scientific framework. The mission of the Consortium is to provide pre-competitive activities allowing interaction among the various organizations in a neutral framework, while providing knowledge transfer between academia and industry. From its humble beginnings in 2002 with 10 companies, the consortium is presently comprised of 36 leading companies (Figure 4) and acts to bridge the communities through:

- Research agendas that solidify the fundamental scientific understanding of TS materials science $\&$ engineering. This is accomplished through identification of scientific areas of immediate benefit to industry in a pre-competitive way. 


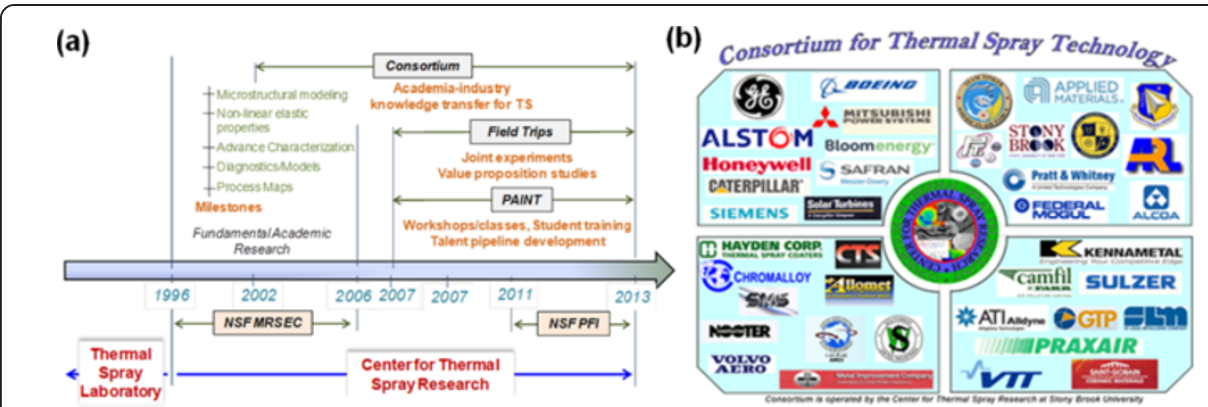

Figure 4 The strategy and outcome of PAINT concept. (a) Time line evolution chart of the concept highlighting early stages scientific advancements and their implementation via PAINT concept. (b) Industries involved in the Stony Brook's thermal spray consortium partnership.

- Demonstration of the scientific advancements in industrial setting to assess the value proposition of innovation. This is enabled through use of industry relevant materials and processes within the demonstration projects. Furthermore, evaluating the relevance of scientific advances through the prism of industrial requirements in design, manufacturing efficiency and product reliability.

- Enhancements to existing industrial methodologies and procedures through infusion of scientific theories, models, and where appropriate suggested modifications. Offer design tools, property databases, measurements methodology and applicable techniques to enable thermal spray coatings as a main stream materials technology

- Networking of leading scientists (academia/industry) for enhanced understanding of the implications of materials and process innovation.

- Training of industrial engineers (and students) in the advanced concepts fostering their accelerated adoption in industrial practice.

- Promoting joint projects among a group of consortium companies to demonstrate innovative ideas especially through academic facilitation of OEM-supply chain partnerships.

- Spinning off industrial interactions and research projects developed specifically around a company's particular needs; a number of Consortium companies are active in joint projects that build upon the foundation laid by the activities.

- Interactions, Internships and employment of student scientists and researchers via orchestrated industrial exposure.

The outcome of the partnership was to advance the cause of establishing efficient, reliable and controllable processes together with enhanced confidence via advanced materials knowledge. A secondary but perhaps a more important outcome is developing a workforce with advanced skills steeped in scientific knowledge.

\section{PAINT field trips}

Traditional approach to knowledge transfer included consortia meetings, training sessions, internships and employment of students etc. However, it was soon realized that these activities were not sufficient to convince industry the value of new technology/ knowledge adoption in the real manufacturing environment. Demonstration activities and training needed to be conducted in a manufacturing environment for industrial 
acceptance. One mechanism to generate interest in these new academic ideas is to conduct on-site experiments in industry with close cooperation with the manufacturing practitioners (e.g. spray booth operators, technicians etc.). This led to the concept of academic-industrial field trips, the emergence of the PAINT concept.

The field trips generally lasted 2-3 days comprising 1-3 University personnel (1 post doc and 1 graduate student with optional faculty involvement) working side-by-side with industrial process engineer and spray booth operator. Typically advanced diagnostic and characterization tools were transported to the industrial site and set-up within a few hours on processes of specific interest to industrial members. Experiments were generally devised jointly between academic researchers and industrial practitioners so as to maximize the benefit to both parties. Typically, 10-20 experiments were conducted per day using industrially relevant materials and processes with a total of 30-50 experiments over a period of 3 days. Following analysis of the results either onsite with the industrial partners or subsequently, a value analysis was conducted from industrial perspectives of efficiency, reliability and performance. In most cases, the summary of the findings was reported back to the rest of the membership during the subsequent consortium meetings. The key element of the field trip was demonstrating value of materials and manufacturing innovations towards enhancing operations and not traditional problem solving exercise limited to specific application needs. The first successful field trip mission was conducted in 2007 involving three members following which 28 such field trips have now been conducted over the last 5 years. Table 1 lists few selected PAINT field trips conducted at industrial consortium member sites. These trips have spanned all parts of the U.S.A. and even locations in Europe. These joint activities coupled with presentation of the outcome to the consortium group as a whole on the efficacy of the approach, has provided a framework accelerated consideration of the innovation. In the next section, we will demonstrate the effectiveness of such a partnership approach in promoting accelerated technology adoption.

\section{PAINT engineer-in-residence programs}

Another activity within the PAINT umbrella is to allow industrial engineers to participate in academic studies to obtain a deeper understanding of the scientific benefits to industrial processes. Stony Brook Center has hosted industrial engineers for short term collaboration (one week) to conduct joint experiments all the way to yearlong industrial sabbaticals involving consideration of both models and experiments. In the case studies presented in this paper industrial engineers were participants in some of the academic test beds. This approach also benefited from better integration of models and advanced diagnostics which are difficult to be fully evaluated in a manufacturing environment.

Active engagement of industry and university participants through field trips and engineer-in-residence programs are critical enablers of PAINT implementation.

\section{Part 3. Illustrative examples of PAINT in practice: science-technology case studies}

In the following sections we discuss specific case studies that bridge the science and technology partnership exemplified through the PAINT framework. The general theme of the strategy is presented in Figure 5, in most cases beginning with experimental observations of salient or peculiar phenomena which followed through with rigorous 


\begin{tabular}{|c|c|c|c|}
\hline Location & Process & Material & Activities \\
\hline \multirow[t]{5}{*}{ Sulzer Metco Westbury, NY } & $\begin{array}{l}\text { HVOF } \\
\text { (gas fuel) }\end{array}$ & Ceramics (YSZ) & Evaluation of torch design \\
\hline & \multirow[t]{4}{*}{$\begin{array}{l}\text { Plasma } \\
\text { Spray }\end{array}$} & Metal (NiCr) & $\begin{array}{l}\text { Process repeatability and } \\
\text { reproducibility }\end{array}$ \\
\hline & & \multirow[t]{3}{*}{ Cermet (WC-Co, CrC-NiCr) } & Residual stress evolution monitoring \\
\hline & & & Process map \\
\hline & & & Feedstock injection optimization \\
\hline \multirow[t]{3}{*}{ MHI, Lake Mary, FL } & \multirow{3}{*}{$\begin{array}{l}\text { Plasma } \\
\text { Spray }\end{array}$} & \multirow[t]{3}{*}{ Ceramics (YSZ) } & Residual stress evolution monitoring \\
\hline & & & Process map \\
\hline & & & Process \& torch variability \\
\hline \multirow[t]{3}{*}{ Stellite Goshen, IN } & \multirow{3}{*}{$\begin{array}{l}\text { HVOF } \\
\text { (gas fuel) }\end{array}$} & Metal (NiCr, CoNiCrAlY) & Residual stress evolution monitoring \\
\hline & & Cermet (WC-Co, WC-CoCr) & Process map \\
\hline & & & Process \& torch variability \\
\hline \multirow[t]{3}{*}{ Caterpillar Peoria, IL } & $\begin{array}{l}\text { HVOF } \\
\text { (gas fuel) }\end{array}$ & Cermet (CrC-NiCr, WC-Co) & Process map \\
\hline & \multirow{2}{*}{$\begin{array}{l}\text { HVOF } \\
\text { (liquid fuel) }\end{array}$} & & Residual stress evolution monitoring \\
\hline & & & Process \& torch variability \\
\hline \multirow[t]{2}{*}{ Tinker AFB Oklahoma, OK } & $\begin{array}{l}\text { Plasma } \\
\text { Spray }\end{array}$ & Ceramic (YSZ) & Feedstock injection optimization \\
\hline & $\begin{array}{l}\text { HVOF } \\
\text { (gas fuel) }\end{array}$ & Cermet (WC-Co, CrC-NiCr) & Residual stress evolution monitoring \\
\hline \multirow[t]{4}{*}{$\begin{array}{l}\text { Volvo Aero Trollhättan, } \\
\text { Sweden }\end{array}$} & $\begin{array}{l}\text { HVOF } \\
\text { (gas fuel) }\end{array}$ & $\begin{array}{l}\text { Cermet (CrC-NiCr, WC-Co, } \\
\text { WC-CoCr, T-800) }\end{array}$ & Residual stress evolution monitoring \\
\hline & $\begin{array}{l}\text { HVOF } \\
\text { (liquid fuel) }\end{array}$ & $\begin{array}{l}\text { Metal } \\
\text { (NiCr, Max Phase, NiCrAlY) }\end{array}$ & Process map \\
\hline & \multirow{2}{*}{$\begin{array}{l}\text { Plasma } \\
\text { Spray }\end{array}$} & \multirow[t]{2}{*}{ Ceramic (YSZ) } & Process \& torch variability \\
\hline & & & Feedstock injection optimization \\
\hline \multirow[t]{4}{*}{ PTI Torrence, CA } & $\begin{array}{l}\text { HVOF } \\
\text { (gas fuel) }\end{array}$ & Metal (NiCr, NiCrAlY, NiAl) & Process map \\
\hline & \multirow{3}{*}{$\begin{array}{l}\text { Plasma } \\
\text { Spray }\end{array}$} & Cermet (WC-Co, CrC-NiCr) & Residual stress evolution monitoring \\
\hline & & \multirow[t]{2}{*}{ Ceramic (YSZ) } & Process \& torch variability \\
\hline & & & Feedstock injection optimization \\
\hline
\end{tabular}

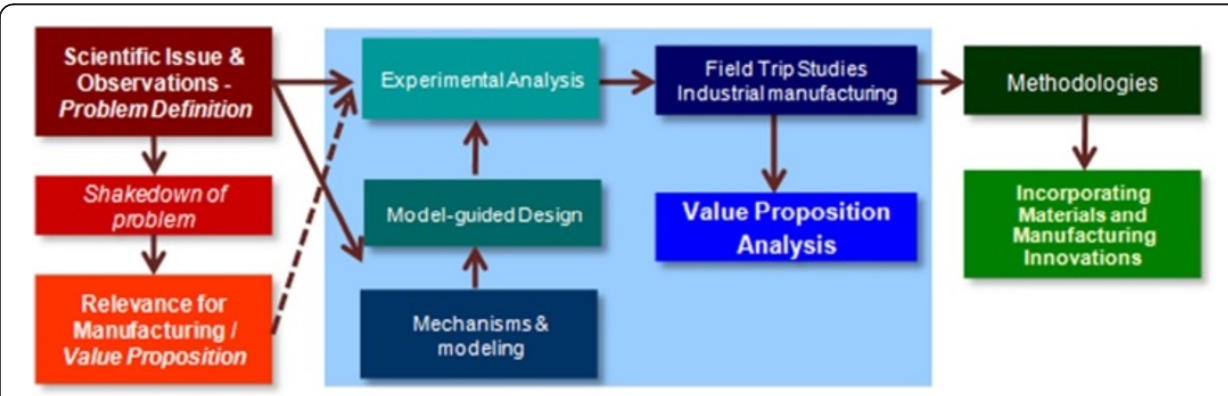

Figure 5 Illustrative description of PAINT case studies strategy. 
scientific observations and models. The implications of these observations on thermal spray materials and manufacturing are then analyzed based on industrial perceptions and metrics. Demonstration studies are conducted to assess the validity of the mechanisms and models to determine the value proposition of knowledge derived modification to manufacturing processes. Ultimately, the fusion of these results through experimental databases as well as robustly tested models will set-up a general framework for Integrated Computational Materials Engineering (ICME) for thermal spray technology. This is discussed in the end of the paper.

\section{Particle injection in DC plasma spray: observations, interpretation, and industrial validation}

In most atmospheric thermal plasma spray operations, the powdered material is injected radially at the exit of the plasma nozzle, following the creation and recombination of the thermal plasma into neutral gases. At this exit, although some level of plasma activity exists, the location is primarily a source of extreme heat associated with the plasma recombination process. Injection of the powder material into this location allows accessing the energy required for melting and acceleration of the particles. Although many variants of plasma injection exist, the above described geometry encompasses the vast majority of modern day plasma spray systems.

It has long been appreciated that injection location of the material into this hot zone is a key parameter that controls both manufacturing efficiency and material/coating quality, as they determine the efficacy of the plasma-material coupling [57,58]. Industrial technicians and engineers have and continue to use empirical insights and experience to optimize this critical processing parameter.

The advent of in situ process diagnostics (optical sensors) and imaging techniques over the last two decades has allowed more critical look at this difficult to access particle-plasma interaction. Recent diagnostics studies carried out in this regard indicated the presence of a geometric "sweet-spot" particularly during processing of low density ceramic particles as described in Figure 6. Optimal injection of refractory low density powders (e.g. zirconia ceramics) into this plasma sweet-spot through control of the carrier gas flow (typically, Argon gas is used to penetrate the powder into the plume) resulted in enhanced energy transfer from plasma to particle, with concomitant increase in particle temperatures and velocities. These, in turn, resulted in more

(a)

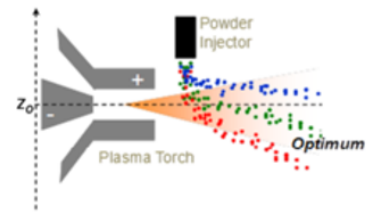

(b)

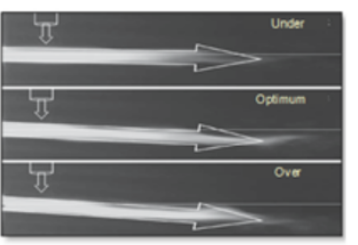

(c)

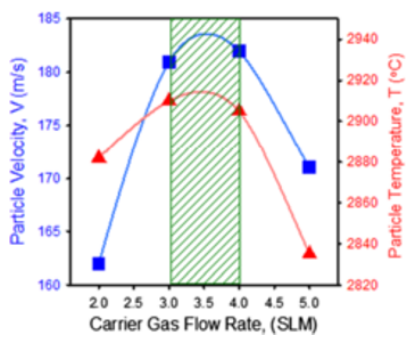

Figure 6 Radial injection plasma spray process and associated optimization. (a) Schematic description of the injection process (b) in situ observation of plume depth and (c) demonstration of maximum energy transfer at the optimum location using particle diagnostics studies. The green band shows the peak locations of particle temperature and velocity with respect to injection location (as represented by carrier gas flow rate). 
uniform particle melting and improved deposition efficiency (defined as the ratio of deposited material to injected material). A series of diagnostics studies with different nozzles, materials and injection parameters all pointed to this singular effect indicative of a geometrically controlled phenomenon. Furthermore, it was independent of material character (within the family of oxide ceramics), process gases, process parameters and device type.

Thermal and fluid dynamic modeling of these interactions confirmed the existence of this geometric sweet-spot and through force balance analysis, it was able to explain the physical mechanisms associated with the effects [59]. In essence, at the optimal injection parameter, the velocity ratio of the orthogonal vector components reaches an optimal value resulting in maximized energy transfer from plasma to particle thereby improving melting efficiency and momentum transfer. Figure 7 illustratively captures the modeling results with details provided in various published articles.

Through the PAINT framework and the field trip program, CTSR students and post-docs were able to conduct similar diagnostics measurements in production plasma spray sites and confirmed the occurrence of this unique phenomenon. Figure 8 describes results from industrial experiments conducted over a two-day period where the maximum energy transfer between plasma and particles were demonstrated using particle temperature, velocity and plume position measurements. The implications of these results are significant: improved process efficiency associated with more effective utilization of the material and overall better control of the process [60].

The outcome of these scientific findings, model based analysis and industrial demonstrations represent a breakthrough in translational research. Many industries have
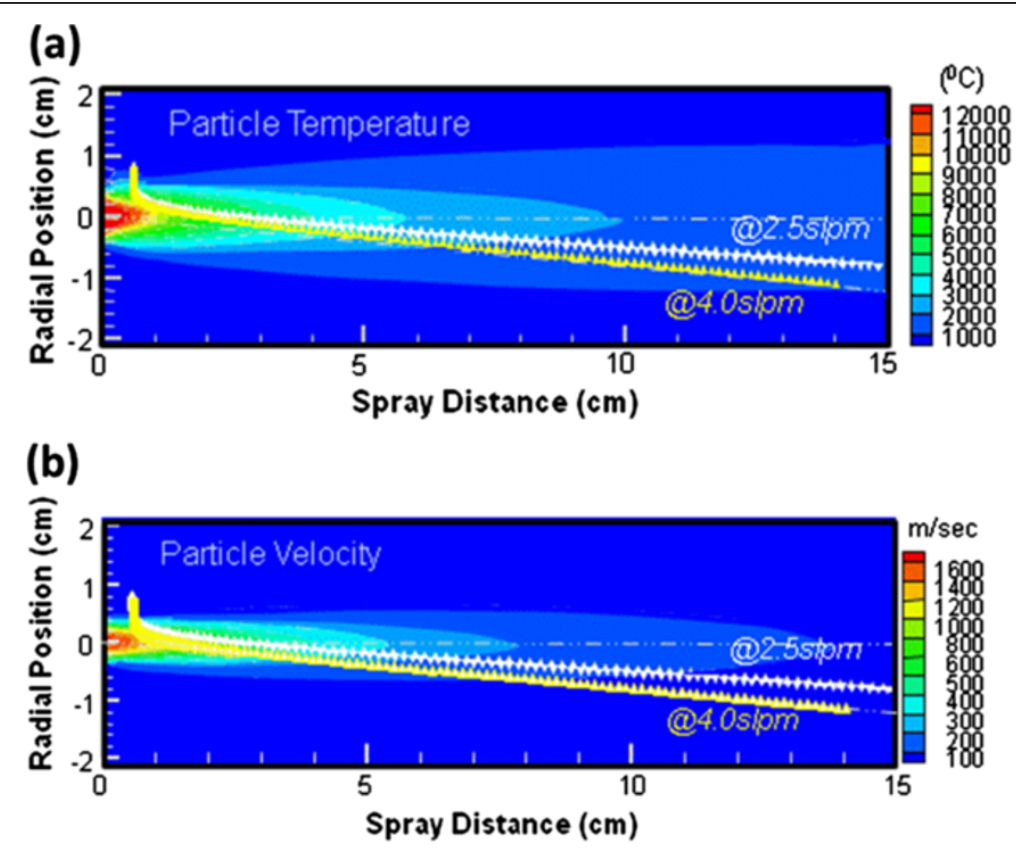

Figure 7 Predicted particle temperature and velocity for different injection conditions obtained through the LAVA-3DP computational model. For the given input plasma parameters and particle size, the optimum for (a) particle temperature and (b) particle velocity occurs at 4 standard liters per minute of carrier gas, resulting in penetration of a majority of particles into the plasma. The model is able to capture the experimentally observed energy transfer maximum (not shown), while providing spatial and temporal distributions of individual particle behavior within the plume [59]. 
(a)

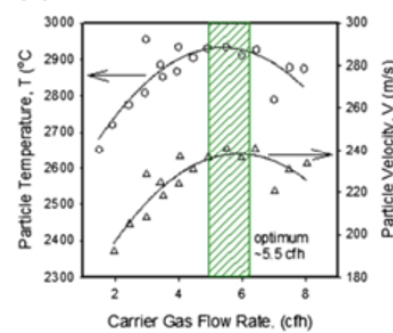

(b)

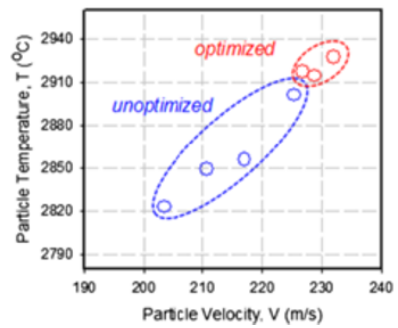

(c)

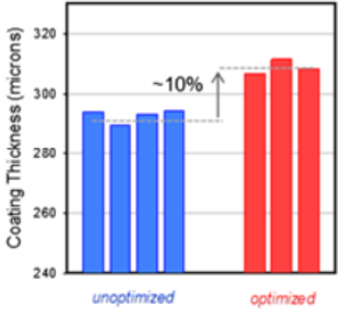

Figure 8 Implications of injection optimization procedure on the particle states and coating thickness as demonstrated in industrial manufacturing sites. (a) Temperature and velocity as a function of injection location as captured by the carrier gas flow rate (b) ensemble particle temperature and velocity for un-optimized and optimized locations and (c) demonstration of $6 \%$ increase in deposit efficiency through the optimization protocol. Studies have also shown that the optimized coatings have significantly improved reliability [60].

recognized the implications of these developments and have already adapted such advances. Moving forward, the fusion of experiments and models also point to a pathway for improved plasma torch design and injectors, computationally optimized parameters for different materials and powders, and a strategy for close-loop control of the process through integration of instrumentation, a priori established models/knowledge and feedback software, i.e., in essence an opportunity for ICME demonstration.

\section{Process maps: synthesis of process diagnostics and models for reliable manufacturing}

Defined the innovation scenario described in Figure 1; in a traditional system driven design and manufacturing methodologies applied to spray coatings, OEMs will typically conduct optimization studies to enhance performance and durability of spray coatings, and identify the resultant microstructural character as a target specification for supply chain adaptation. In this linear approach, the coating applicators can choose different manufacturing pathways (within limits) to meet the specification window. Most OEM products may involve multiple coating vendors such that an "equivalent" product will likely result from different manufacturing parameters. For instance, different vendors may employ different types of spray torches or feedstock materials, resulting in different processing parameters to meet the characteristic window of the coating specification. This, in turn, has shown to introduce variances in performance and durability at all levels of the coating life cycle and, as such, a concern from the perspective of design and manufacturing innovation.

As pointed in the earlier case study, in recent years, in situ particle diagnostics and models have provided significant insights into understanding of the complex dynamics of plasma spray manufacturing of advanced coatings. A concurrent strategy extending from optimized injection approach is the ability for controlled navigation of particle properties to produce optimized microstructure and properties of thermal spray coatings.

Process maps provide a science and technology framework for developing a navigation tool for the coating manufacturing enterprise. Process maps are integrated relationships linking processing-microstructure-properties [37,61,62]. These maps are generally designed based on statistical design of experiments using a-priori identified critical variables. These experimental maps can be augmented with analytical or 
numerical models which can guide experimental design, interpretation of the experimental data and interpolation/extrapolation of the experimental boundaries. Figure 9 provides a framework of such a process map concept for plasma spraying. For complex processes such as plasma spray there are numerous variables that govern the processstructure-property relationships and it is often difficult and inefficient to sort through the various relations. Advanced mapping concepts not only provide an optimization strategy but also a methodology to assess industrially relevant issues of efficiency and reliability.

There are two domains over which these maps are constructed for thermal spray. The first step involves mapping the characteristics of particle spray stream as governed by their thermal and kinetic energies (the key variables). This is a necessary first step to quantify the role of spray device and parameters on the spray plume. Advanced particle diagnostics allows for rapid and expansive characterization of these particle streams thus captured and represented through the first order process map. Overlaying the effects of particle characteristics on deposit microstructure and coating properties will result in a second order process map. Additional process parameters such as deposition rate, substrate temperature, spray rate, spray angle etc. are also included into such mapping schemes. The combined interpretation of all of these effects will enable comprehensive description of the process-structure-property relations.

An example of a process map created from experimental diagnostics data during atmospheric plasma spray processing of zirconia thermal barrier coatings is shown in Figure 9. The figure displays the range of achievable particle thermal and kinetic histories and the impact of key variables in influencing the particle properties as represented within the map. This first order process map in some sense is a manufacturing analogue of modern day GPS (Global Positioning System) for automobiles. In essence, they provide both location and direction to reach a destination. Such maps provide quantitative descriptions of the process locations along with process vectors that would enable one to access them. Overlaying material properties resultant from coatings synthesized from conditions described in the first order map will result in a $2^{\text {nd }}$ order map shown in Figure 9. For example, a contour map of coating thermal conductivity is constructed from the particle property data. The linkage between first and $2^{\text {nd }}$ order maps now provides a framework for integration of coating design and manufacturing.

(a)

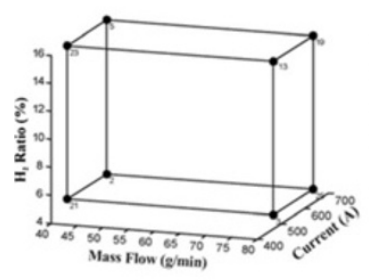

(b)

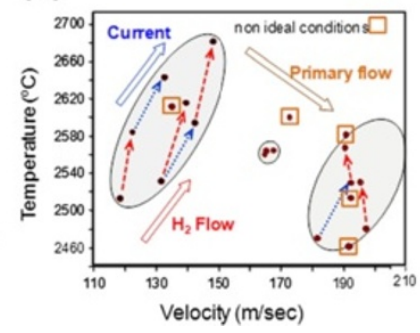

(c)

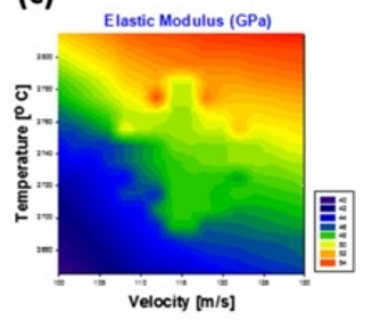

Figure 9 Synthesis of plasma spray process maps from advanced optical diagnostics. (a) Statistical design of experiment (DoE) to generate a range of operational conditions [37] (b) experimental particle diagnostic results and associated control vectors for the operational parameters (mass flow of gases, current and hydrogen ratio) (c) the $2^{\text {nd }}$ order process map presenting the relationship between particle states and elastic modulus, an actual coating property. 
Process maps also provide an opportunity to link processing with microstructure. The thermal and kinetic energy of the particles will affect overall porosity as well as the type and architecture of the defects. Examples of such process-microstructure correlations are available in numerous published references [33,37,47,50,52,56,61]. Industry has typically relied on microstructural observations with respect to design and manufacturing specification. However, there is a realization that due to the assortment of defects, their multiscale nature, and significant local and variability microstructures are difficult to robustly quantify from a mapping perspective. Although they will likely be used as an important measure coating quality, the focus here is to link process to design relevant properties.

The process map approach benefits both the OEM and supply chain as it provides connectivity between both top-down and bottom-up developments. For example OEMs can develop coating architectures that are the most optimum for performance while the suppliers can innovate within the process and materials template for enhancement of manufacturing efficiency and reliability. In situ diagnostics and maps enable in these developments a foundational framework as well as an intra-company process database. Process maps also allow identification of deviations from the expected there by alerting the relevant stakeholders, the impending changes and its implications.

Over the years, advanced computational models have also been developed for plasma spray processes $[24,35,36]$. Given the complexity involved in the process, modeling efforts require many facets of information including thermal plasma physics, fluid dynamics, heat transfer and notably thermo-fluid-materials interactions in a highly dynamic turbulent flow environment with steep thermal gradients. Researchers involved in plasma science have developed comprehensive codes based on local thermodynamic assumptions and this has served as a basis for further consideration from the process modeling point of view. Early work at Idaho National Laboratory (INL) set-up such a thermal plasma code for direct current thermal plasmas: termed LAVA. This code continued to develop at INL for more than a decade [63]. In the late 1990s, a partnership between INL and Stony Brook's Center for Thermal Spray Research allowed expanded developments, particularly in the area of particle flame interactions. Incorporation of materials physics allowed for consideration of melting, evaporation, oxidation (in case of metals) and decomposition (LAVA-P for LAVA with particle interactions). During the last decade, this initial 2D code was expanded to incorporate 3D effects to provide more realistic assessment of processing effects. Finally, combining the process code with impact and coating formation simulations allowed for a fully integrated process modeling system for plasma spray.

Most of the modeling effort to date focused on process understanding and phenomenological descriptions with some predictive capability. As discussed earlier, the model was able to effectively capture the injection sweet-spot phenomena and offered quantitative interpretation of the observation. In the same way, the model also allows for virtual synthesis of plasma spray process maps in particular to capture the $1^{\text {st }}$ order effects connecting process parameters with effluent particle properties (particle thermal and kinetic energies at the location of interest). Modeling activity has also been extended for complete description of particle states as a function of process parameters enabling virtual simulation of process maps. This is described in later sections, as an enabling element of future ICME development for plasma spray process. 
Several field trip studies have been conducted to espouse the benefits of such mapping and modeling concepts in industry. Typically industrial process parameters are proprietary, as such the axis of the process map interpretations have been normalized and presented as relative values. An example of one such exercise is provided in Figure 10. The results present both first and second order maps for the zirconia systems applied under industrially relevant conditions but using the diagnostics tools and methodologies emerging from academic work. In some sense, normalized maps provide a framework for effective OEM-supply chain interactions. From an OEM point of view, the property data can be used for design and thus can use the maps to guide the supplier with respect to process loci of interest while the supplier has the opportunity to engineer the process for reliability and efficiency providing the flexibility in terms of performance space to the OEMs. Finally, for other partnership examples, LAVA modeling was used for plasma torch developments and verification of performance of advanced nozzle designs.

\section{Application of beam curvature theory for coating design and manufacturing reliability}

The impact and quenching of thermal sprayed droplets results in anisotropic layered structures accompanied by generation of large formation stresses. Typically, the solidification and cooling of the droplet material is constrained by the substrate or underlying solidified coating and thus puts the newly solidified material in tension. The so called quenching stresses can be very significant reaching levels of more than $1 \mathrm{GPa}$ for individual metallic particles due to the fine grain sizes and associated Hall-Petch dependence of yield strength [7]. Relaxation mechanisms such as debonding and sliding result in lowering of these average stresses but still significant for most metallic systems. In the case of ceramics, the high quenching stresses are quickly relieved through mudcracks resulting in lower overall average stresses that are beneficial from the strain tolerance point of view. Additional stresses arise from thermal mismatch between the coating and substrate as well as through peening effects in high velocity thermal spray technologies (e.g. supersonic combustion spray, detonation-gun and cold spray processes).

The thermal spray industry and scientific community have long been challenged in terms of robust characterization of the mechanical properties of spray coatings. The
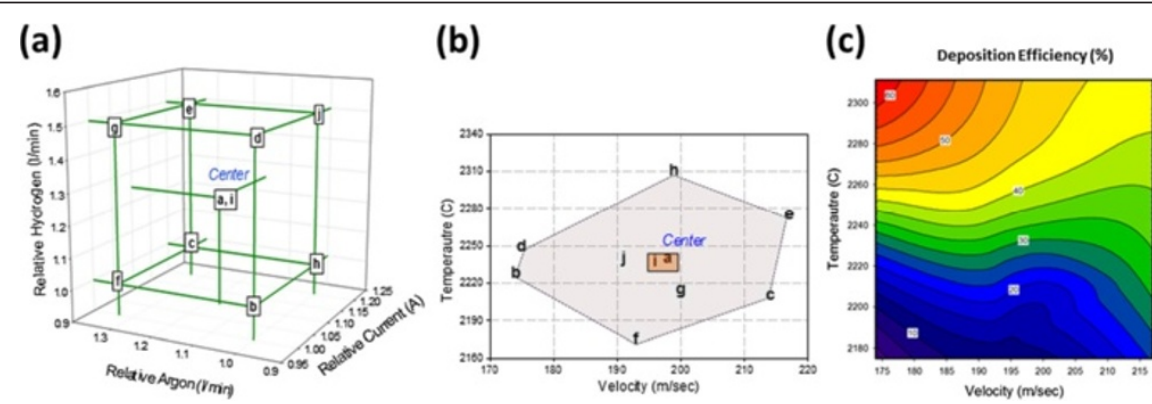

Figure 10 Demonstration of the process map concept in industrially relevant conditions. (a) Design of experiments as represented in relative scales using relevant process conditions (b) first order process maps based on DoE and diagnostics and (c) $2^{\text {nd }}$ order process maps identifying locations of maximum process efficiency. Other second order maps of properties are also available which provides industry tools to identify optimum process location for performance with simultaneous understanding of efficiency and reliability. 
presence of residual stresses compounds the interpretation of mechanical properties. One approach to understanding both evolution and final residual stresses as well as a first order assessment of mechanical properties of spray coated materials is through the use of in situ beam curvature monitoring, similar to those used for decades by the electronics and plating industries $[64,65]$. Kuroda et al. in Japan pioneered the use of such beam curvature methods for thermal spray in the late 1980s and subsequently this work was followed by Tsui and Clyne through enhanced interpretation of the underlying phenomena through analytical models [7,66-69]. In the 1990s, work at Stony Brook has not only expanded the scientific understanding of the beam curvature mechanisms for thermal spray, but have also extended the capability for advancing process control and industrial coating specification [62]. An illustrative description of the in situ beam curvature monitoring concept is presented in Figure 11. Figure 11a is an illustration of a non-contact curvature monitoring using multi-point displacement measurements on a near uniaxial beam but is similar to the work by Kuroda using contact measurements. Figure 11b shows the raw curvature and temperature evolution data during deposition and cooling. (the steps in the curvature and temperature result from spray torch traversing resulting in beam deflection due to plasma impingement). Figure 11c shows results for a plasma spray sample which shows predominantly a positive (quenching) stress evolution while the high velocity oxy-fuel sample show negative stress evolution resulting from impact related peening stress.

We present two case-studies related to this capability: one each for metallic and ceramic systems along with critical steps aimed at industrial consideration of these scientific developments. In the latter case, the curvature theory was expanded to include non-linear effects which provided an enhanced description of the microstructureproperty relationships [70].

\section{In situ monitoring of coating formation dynamics}

Knowledge of residual stresses is of particular importance in applications involving contact damage situations such as wear/friction as well as for components subjected to fatigue loading (aircraft landing gear, earth moving equipment, heavy machinery, steel mills etc.). Typically, coatings used in these conditions require very low porosity, high hardness, and toughness. Metallic alloys (Ni, Co and Fe alloys) and cermets (e.g. WC$\mathrm{Co}, \mathrm{CrC}-\mathrm{NiCr}$ ) are the primary material choices employing high velocity thermal spray processes such as supersonic combustion thermal spray (high velocity oxy-fuel-HVOF) or detonation spray systems.

(a)

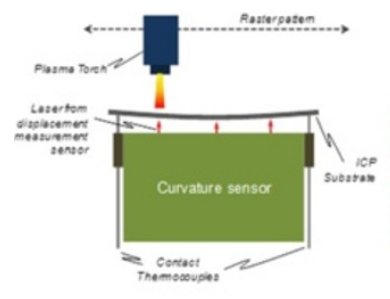

(b)

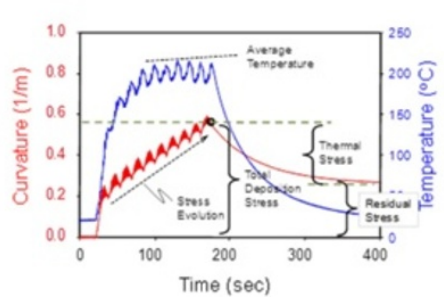

(c)

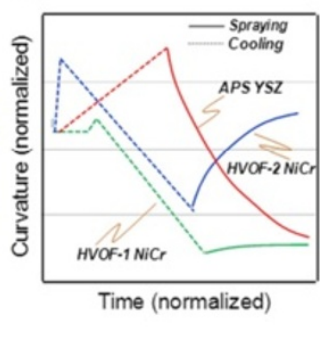

Figure 11 In situ beam curvature monitoring concept for measuring coating properties. (a) Instrument description and process procedure (b) curvature and temperature evolution during deposition and cooling (c) fitted curvature data displaying different stress evolution dynamics for metals and ceramics [67]. 
These high velocity spray systems not only allow for synthesis of nearly dense coatings, but the impact forces can induce significant peening stresses in ductile metallic systems resulting in highly compressive coatings [61,71-73]. The operative mechanisms involved in stress evolution dynamics and coating formation are dependent on both the material character and process parameter. Specifically, three forms of stresses contribute to the overall coating residual stresses. They include quenching stresses associated with phase change and thermal cool down from molten state (generally in tension); peening induced compressive stresses; thermal mismatch stresses associated with cool down of the two layer system from processing temperature to ambient temperature (which can be either in tension or compression depending on the mismatch signs between coating material and substrate). The quenching stresses depend on extent of melting of the particles in the plume while the peening stresses depend both on particle kinetic energy and coating material's intrinsic ductility and strain hardening.

The complex interplay among the materials, processes and operative mechanisms often leads to long iterative trials among material selection, process optimization and characterization. Furthermore, process induced effects can influence the extrinsic coating properties of hardness and adhesion. Through a combination of advanced diagnostics, process maps, in situ beam curvature monitoring along with mechanistic understanding of the phenomena, it is now possible to utilize these tools and scientific methodologies for industrial process optimization.

Figure 12 illustrates the connections between process parameters, particle states and stress evolution dynamics for HVOF processing of NiCr. In this study using a single HVOF process, propylene as fuel and a series of process conditions were scanned through a first order process map (Figure 12a). Subsequently coatings from four regions of the process map, designated as A, B, C and D, were deposited onto the curvature sensor. Coatings fabricated using high velocity, low temperature conditions (B, D) display a larger contribution of compressive peening stresses compared to those deposited at higher thermal energy conditions (A, C). Among the two higher velocity coatings, B with lower temperature and higher velocity displays a larger prevalence of peening stress. Figure $12 \mathrm{~b}$ shows the summary result the component residual stresses obtained from the raw curves (not shown) including the final residual stresses resultant after thermal cool down from spray temperatures. The curvature derived stress evolution curves indicate that formation dynamics is as important as end stresses in these coatings.

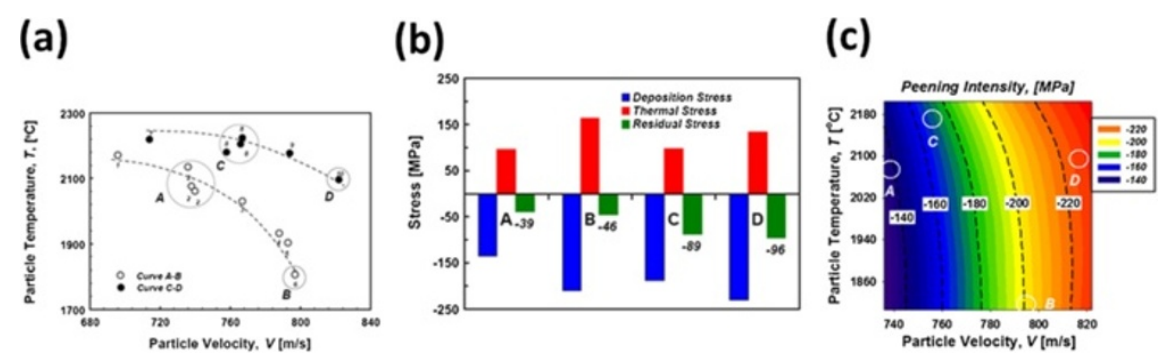

Figure 12 process property correlations for $\mathrm{NiCr}$ coatings deposited via high velocity combustion spray process. (a) The first order process map exhibiting particle state parameters for various conditions (b) curvature derived residual stress differentiating the role of particle parameters on deposition and residual stresses for four the selected processing conditions (c) 2nd order process maps depicting peening intensity profiles for various particle state conditions obtained from curvature measurements [61]. 
The resultant effects of such parametric exploration and in situ monitoring can be visualized using a second order process map. Shown in Figure 12c is a peening intensity map that is obtained by overlaying the peening intensity as obtained by curvature measurements on the particle thermal -kinetic energy diagram captured by the particle temperature and velocity measurements.

These maps are not only useful visualization tools to depict properties for design purposes but also provide insights into the operative mechanisms. The peening intensity maps will also provide a direct correlation to coating hardness, modulus and wear performance [61].

The peening intensity parameter can also be analytically and numerically modeled and as such provides a pathway for model guided material selection and parameterization. During the impact of a particle propelled at high speeds, the surface impacted conforms as the particle deforms to a pancake shape called "splat". This occurs in a very short fraction of time (e.g. 4-5 microseconds). Both, the particle and the substrate are subjected to high strain rates and high deformation in a very localized area. This added to the heat contribution of the particle and the torch makes necessary the use of modeling tools to identify key parametric effects on the stress evolution. The model of choice here is the Johnson-cook impact model that expresses the stress dependence on strain, strain rate and temperature for a given material. This model has been used to analyze the impact of a particle as shown in Figure 13a, where the maximum compressive stress and depth profile are extracted to predict after successive impacts and quenching of several splats for the final residual stress profile of the substrate/coating system. Once the model has been developed and correspondingly compared to actual measurements, the response of the main variables (such as particle temperature, particle velocity, substrate temperature) has been studied to identify the process dependency and sensitivity. In Figure 13b, the stress profiles produced by a particle of SS-316 impacting at $600 \mathrm{~m} / \mathrm{s}$ over a substrate initially at various temperatures is presented. The hotter the surface is, the lower the induced stresses are, due to relaxation by yielding. This analysis presents another opportunity for control process induced peening stresses, not only by particle state control but also by substrate temperature control which can be implemented by external cooling, or feed rate

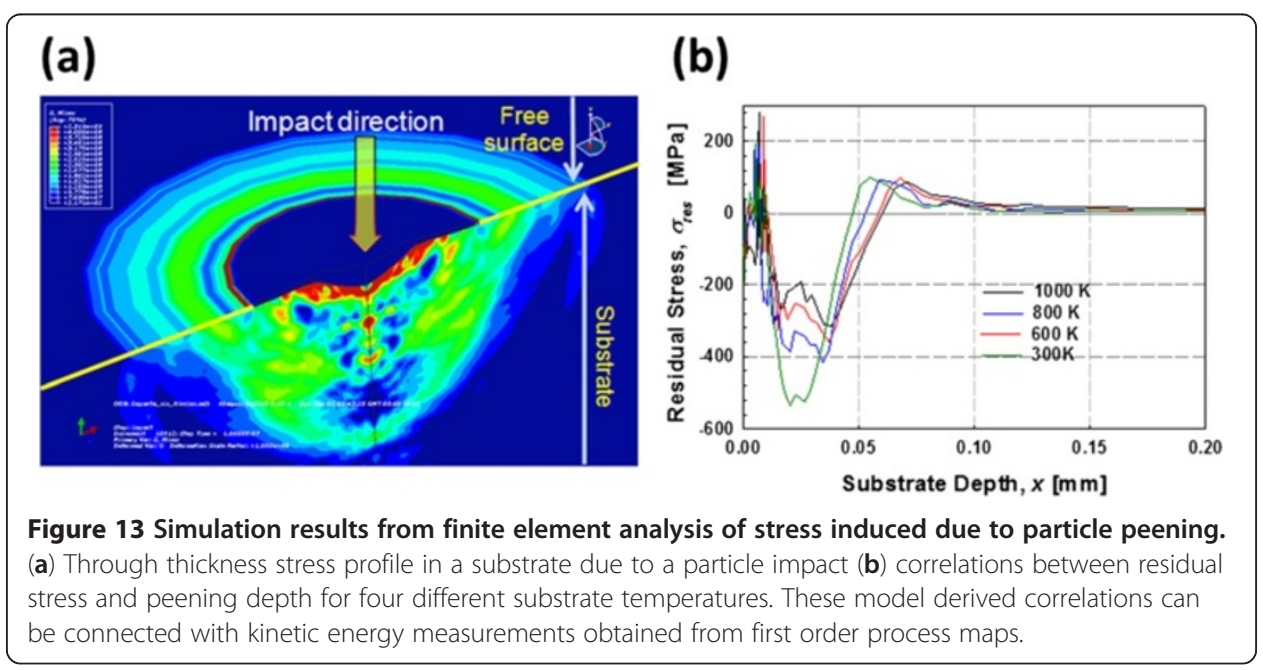


control. The modeling of particle impact has significantly raised our understanding of the coating formation dynamics and benefitted the thermal spray community by demonstrated strategies for coating design.

The utility of the in situ stress monitoring, modeling and peening intensity map description for industrial design and manufacturing was demonstrate through a multiindustry field trip. As mentioned earlier thermal spray industry has developed and uses a variety of different torch and material configurations to achieve the same application goal. This is particularly true for high velocity thermal spray systems as different combustion gases (hydrogen vs kerosene or oxygen vs. air), nozzle types (straight bore vs. deLaval type), powder injection (axial vs. radial) and total gas and thermal input. Although the ultimate microstructure may appear similar, the journey to arrive at this end coating can be substantially different, particularly with respect to residual stresses and properties.

To assess these differences, one common powder material $(\mathrm{NiCr})$ was processed at several industrial sites at their nominally optimum processing conditions. The integrated results are captured in Figure 14 starting with (a) 1st order process of map of thermal and kinetic energies (b) in situ stress evolution as a function of the particle kinetic energy obtained from 1st order map and (c) hardness as a function of the stress evolution. The results explain the differences in coating hardness (of the same material) as synthesized from different industrial process conditions and also point to the underlying origin of the differences. The explored map of particle temperature and velocity is significantly broad and considered not achievable by a single process, which assures the generalization of the results. The combination of high particle temperatures and low speeds (e.g. plasma spray process conditions, shown as APS) result in high quenching stresses and lower peening stresses that ultimately reduce the hardness of the coating (the overall summation of tensile-quenching and compressive-peening is shown as evolving stress). The higher the particle velocity always increases the peening effect. Hardness is found to depend monotonically with the induced process stresses during formation. Higher the induced compressive stress is, the higher the hardness of the coatings results. This is not an implicit relationship of properties but a result of a processing induced effect measured indirectly by the residual stress and their effect reflected in properties. Property range may vary significantly with respect to the bulk
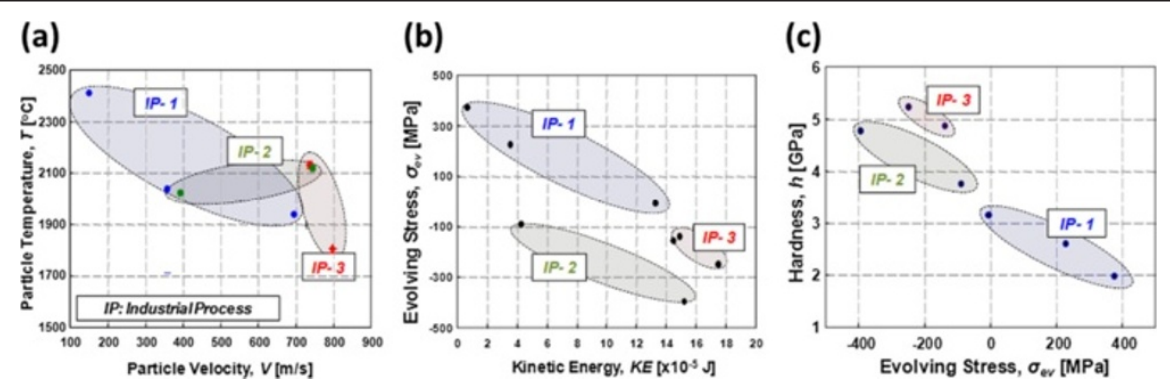

Figure 14 Industrial demonstration of the particle parameter effects on residual stresses. (a) $1 \mathrm{st}$ order process maps displaying characteristics of different industrial spray processes (b) relationship between stress evolution (as obtained from curvature measurements) and kinetic energy and (c) correlation of residual stresses to coating hardness [61]. Such integrated design maps enable both materials design and manufacturing optimization. 
property for TS coatings. In the present case, the property ranges from half of the bulk property to almost two times the same one. This type of findings justifies the detailed assessment of systematic studies.

These field trip assessments and integrated assimilation of the information can benefit each of the industrial stake holders in different ways. For the manufacturing companies, it provides tools for optimization and control of the process. For the OEMs, it provides a database and map for coating selection and specification. For the knowledge enhancement partners and coating material/system developers, it provides a pathway for materials and process innovation. Combination of models, experiments and databases can also enable the ICME framework.

\section{Non-linear models define coating mechanical properties}

The bilayer curvature response of the coating-substrate system also provides information on the elastic properties of the coating. Knowledge of coating thermal expansion and the continuous measurement of the curvature change with temperature to the first approximation can be used to extract the elastic modulus of the coating. However, a careful look at the curvature-temperature relations obtained via continuous monitoring of curvature during cooling following deposition indicated non-linear relations for these porous ceramic coatings. Repeated low temperature thermal cycling in a controlled thermal environment confirmed these observations (Figure 15a) and further suggested that these curvature-temperature relations during heating and cooling cycles follow different paths in the case of plasma sprayed zirconia coated metallic substrates.

Detailed experimental analysis of the forward and reverse relations suggested that these behaviors are the result of the unique porous and lamellar character of the spray coated ceramics. The opening and closure of pores and cracks during the heating and cooling cycles result in non-linear elastic behavior while the sliding among the loose splat interfaces causes hysteretic response. Together, the behavior is collectively described as anelasticity and these properties are strongly dependent on the unique ceramic microstructure resultant from the plasma spray process. Furthermore, the anelastic response of these ceramic coatings is an indicative of coatings' compliance, the ability to withstand high strains without generating large stresses into coatings. The compliance of ceramic coatings is one of the key factors that determine durability of thermal barrier coatings.

(a)

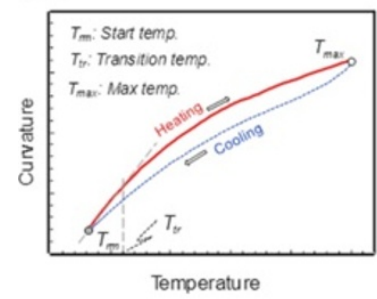

(b)

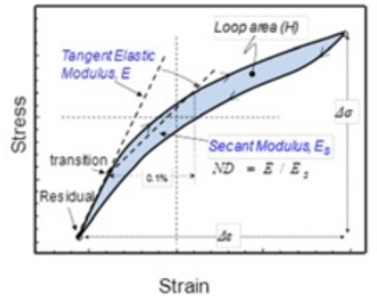

(c)

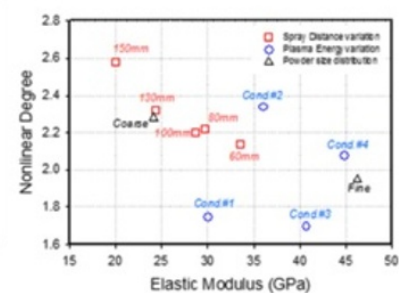

Figure 15 The measurement and quantification of anelastic parameters using bi-layer curvature measurement method. (a) Description of the non-linear elastic behavior as acquired from beam curvature and temperature monitoring $(\mathbf{b})$ associated conversion of the stress-strain relations obtained from modeling (c) representation of the non-linear elastic properties for materials made under various spray conditions and spray distances [74]. 
Fundamental science and models Since the curvature-temperature relations are dependent on thermal expansion coefficient and respective thicknesses of coating and substrate, it is desirable to convert the experimental results into stress-strain $(\sigma-\varepsilon)$ relations for their true property comparisons. Figure 15a shows a typical curvaturetemperature $(\kappa-T)$ plot for a plasma sprayed ceramic coating on a metallic substrate. $\sigma-\varepsilon$ conversion of the plot is carried out separately for forward (heating) curve and reverse (cooling) curve. As marked in the figure, there exists a transition temperature $\left(T_{t r}\right)$ within the experimental temperature range $\left(T_{r m}-T_{\text {max }}\right)$, which is a signature of a transition from linear to non-linear behavior of the coating. At room temperature, in general, a ceramic coating contains a residual stress, which is a resultant of stress generated during deposition and cool down process. The $T_{t r}$ in the $\mathrm{k}$-T curve (Figure 15a) is indicative of initiation of defect movement phenomenon in the coating structure after overcoming the compressive residual stresses. Below $T_{t}$, the coating behaves in conventional linear elastic mode in the absence of any defect defomating in part due to the presence of compressive stresses. It is noted that since the heating and cooling curves are different, the values $T_{t}$ generally, are different for the two curves.

A modified version of Ramburg-Osgood model for porous materials is utilized to generate $\sigma-\varepsilon$ relationship (Figure 15b) for forward and reverse curves of $\kappa-T$ measurements (Eq. 1) [70]. The model first generates a $\sigma-\varepsilon$ relationship for the linear part (below $T_{t r}$ ) of the $\kappa-T$ curve using linear elastic solid properties of coatings. Slope of the linear curve is referred as elastic modulus $(E)$ of the coating. Later, the remaining nonlinear section of the curve is fit to the proposed model. Two fitting parameters $\sigma_{O}$ and $n$, known as reference stress and power-law exponent, are estimated through an inverse analysis using Kalman filter [70], which conducts several iteration until the best convergence within the allowable limit. The filter not only computes solutions faster than other adaptive filtering methods for non-linear problems (reference, Nakamura), but also is capable of eliminating noise from the measurement data.

$$
\varepsilon= \begin{cases}\frac{\sigma}{E}-\frac{\left|\sigma_{T}\right|^{n}}{E \sigma_{0}^{n-1}} & \text { for } \quad \sigma<\sigma_{T} \\ \frac{\sigma}{E}+\frac{\left(\sigma-\sigma_{T}\right)^{n}-\left|\sigma_{T}\right|^{n}}{E \sigma_{0}^{n-1}} & \text { for } \sigma \geq \sigma_{T}\end{cases}
$$

Where, $\sigma, \varepsilon, E$ and $\sigma_{T}$ are stress, strain, elastic modulus and transition stress of the coating [70].

The conversion of $\sigma-\varepsilon$ from measured $\kappa-T$ facilitates a detailed comparison of coatings with different physical properties, such as stiffness, thickness, density etc. However, a simplified comparison of various coatings requires further quantification of coatings' anelastic properties. Therefore, a two parameter approach was adapted to uniquely define coating's non-linear properties; elastic modulus $(E)$, slope of the forward curve below $\sigma_{t r}$ and non-linear degree (ND) which is the slope of $E$ and the secant modulus of the same curve from $\sigma=\sigma_{t r}$ and $\sigma=\sigma_{\varepsilon=0.1 \%}$ [74]. Such quantification of $\sigma-\varepsilon$ behavior of coating was successfully applied to various coatings deposited following our process map design approach, and it was observed that coatings with minimal changes in parametric design of process can uniquely be identified by their $E$ and ND values. Figure 15c shows a map exhibiting a simple representation of the coatings with different process parameters, such as spray distance, plasma energies and feedstock power size. 
This E-ND space serves as a feedback to our process map to produce a desired coating with a few iterations.

The simplicity in utilizing these non-linear parameters as a representation of the properties of these complex materials, this ex situ bi-layer curvature technique was introduced to most of the field trips with ceramic processing. Figure 16a and 16b shows one of the applications of the $E$-ND space for coatings, which is the repeatability assessment of plasma sprayed coatings, one of the many issues with plasma sprayed thermal barrier coatings. The results presented in Figure 16a provide an estimation of variability in coating sprayed at different sites, including Stony Brook. It was noted that coating repeatability varied from one spray site to another, and this information can be captured utilizing the $E$-ND parametric space. Similar application of estimation of coatings' repeatability, sprayed with and without adaptation of injection optimization at one of our field trip sites Figure 16b. The results correlate well with the improved process repeatability associated with optimized particle injection experiments as shown in Figure 8. Figure 16c shows an example of how a parametric design approach in processing can be applied and monitored through $E$-ND map. In the figure, the coatings with parametric space- 1 were fabricated at one of the field trip sites. On the other hand, those with parametric space- 2 were strategically deposited using our process map approach targeting higher overall anelasticity, i.e. higher nonlinear degree and lower elastic modulus. In summary, the $E$-ND parametric space can not only be applied to the day-to-day coatings repeatability assessment, but also provide a guide to design process parameter to produce coatings with desired anelastic properties.

Further development of these maps is currently incorporating large quantity of data from field trips experiments. In addition, a model guided design of experiment has been carrying out at CTSR to carefully map and develop a better understanding the coatings properties with fine and coarse changes in processing conditions. This database of maps will help us design more efficient coatings with significantly improvement in coatings repeatability.

\section{Enabling new opportunities in functional oxides}

Deposition technologies for functional oxides are an emerging area of interest particularly in the context of thick film multilayer devices. Applications range from solid oxide

(a)

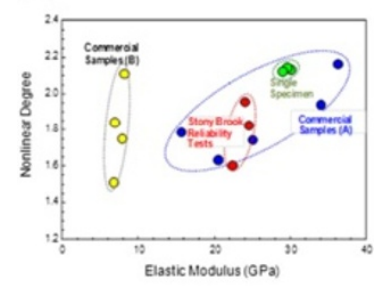

(b)

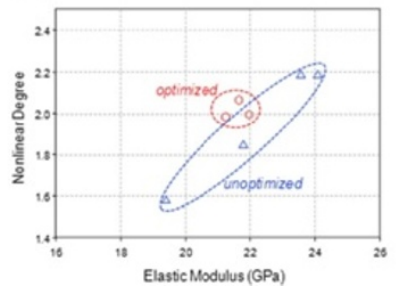

(c)

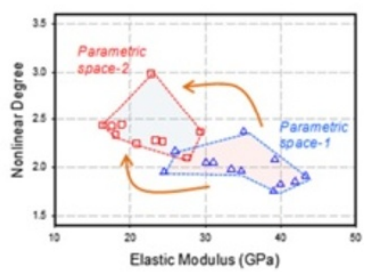

Figure 16 Evaluation of measured coatings' non-linear properties as a tool for process monitoring. (a) Non-linear elastic property maps constructed from industrial samples displaying a measure of variability associated with day to day manufacturing [60]. (b) Non-linear maps used to assess efficacy of process control e.g. through injection optimization to reduce coating variability (c) the maps, obtained from industrial coatings, demonstrating with mapping strategies to optimize coating properties based on specific

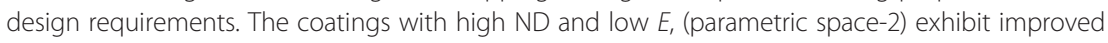
mechanical compliance, one of the key requirements of ceramic topcoat of TBCs, utilizing the E-ND map as a potential coating design tool. In general, the maps can provide an assessment of process control, design and reliability. 
fuel cells, solid state batteries, electromagnetic applications in communication devices and a wide range of sensors. Thermal spray offers unique pathway for deposition of functional oxides due to their high deposition rates, extraordinary materials flexibility, 3D fabrication capability and low substrate temperatures. Despite these advantages, very limited application of thermal sprayed functional oxides exist and industry only now slowly getting interested in this application portfolio [3-5]. Beyond the known process induced defects such as cracks, porosity and interfaces, the non-equilibrium nature of thermal spray affects the structure, composition, grain size and stress, contribute to diminished electrical properties and functional performance. In recent years, the scientific methodologies discussed in the above sections have been practiced to extend the capabilities of thermal spray for functional systems. Notable is the effort aimed at multilayer fabrication of solid oxide fuel cell systems where the ability to deposit several different materials and microstructures is enabled by thermal spray processes.

The concept of process maps, in situ stress/property monitoring, microstructure evolution dynamics, and property assessments shown for the $\mathrm{NiCr}$ and zirconia systems earlier can be readily extended to functional oxide but can add requirements involving phase stability, chemical stoichiometry, disorder all of which will be affected by the process needs to be considered [55]. The latter is highly complex to interpret and map, but direct assessment of functional property assessment and linking these effects to process parameter can aid in accelerated materials and process development.

One such example of a process map application to functional oxides is for Strontium doped lanthanum manganite (LSM). LSM with a perovskite crystal structure is a high temperature electrical conductor and exhibits excellent electrochemical performance. They find applications in electronics, fuel cells and sensors. Thermal spray deposition of LSM can be complex resulting in mixed phases, metastability, loss in stoichiometry, change in oxidation states and local/global gradients in chemistry. These attributes are strongly dependent on process conditions and the spray environment. As is noted in Figure 17, process maps allow for navigation of the process-material interactions and enable optimization of functionality. In this case, the functionality is assessed by the high temperature electrical conductivity of the sprayed material which is controlled by the particle states as represented by the temperature and velocity. Additional properties such as magnetic permeability or ionic conductivity can also be represented through

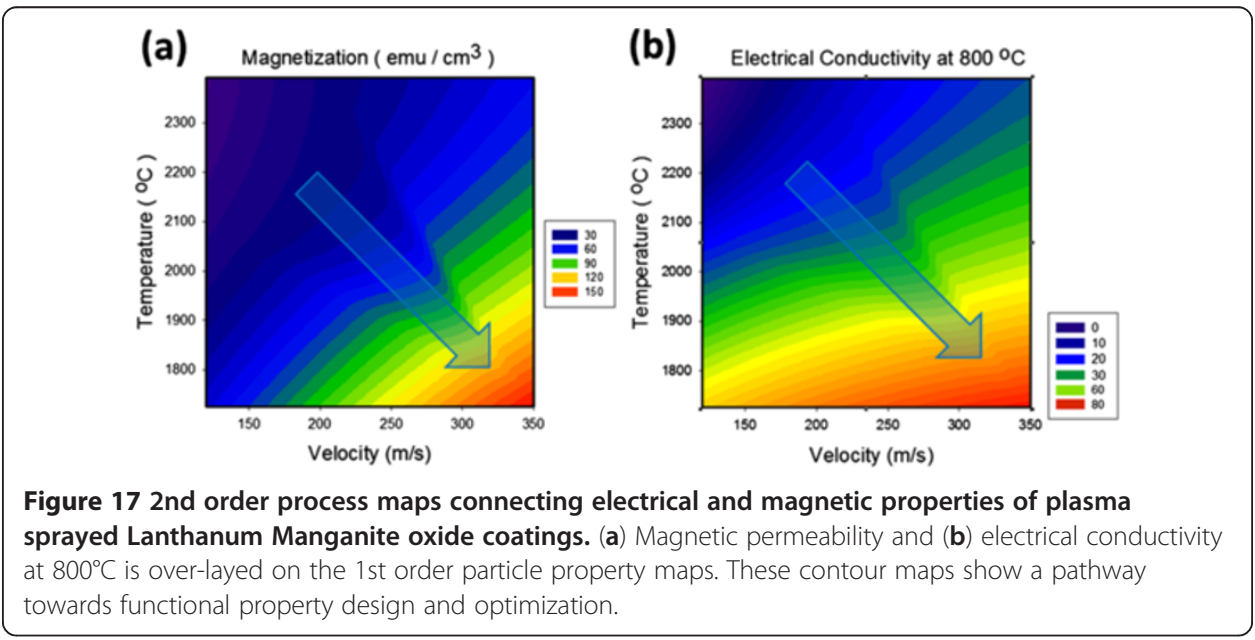


these maps along with mechanical properties such as modulus and residual stresses. Modeling functional response of multicomponent oxides is itself a complex process. When combined with the microstructural attributes of thermal sprayed systems, the system at this point is intractable via modeling. Nevertheless, the models and methodologies developed generally for ceramic oxides can be extended from process optimization point of view. Such studies are now underway. Finally, industrial linkages in this area of thermal sprayed functional oxides are only now developing as the application opportunities are only now emerging. Partnerships have been initiated in this arena and already paying rich dividends to industrial developers through maps, databases and tools for characterization. At the very least it will allow industry to make a rapid assessment of the technology potential for various classes of functional oxide systems.

\section{Outcome of PAINT case studies}

The advanced concepts demonstrated through the case studies are now being implemented at both system integrators and application providers. Specific implementation of the concepts remains proprietary to individual companies and as such difficult to provide demonstrative examples. However, several anecdotal examples of advanced technology implementation exist.

- Innovations demonstrated in the first case study on particle injection have resulted in development of simple low cost sensors and control strategies that are now in advanced stages of implementation consideration.

- Both system producers and manufacturers have embraced the process map concepts. From system integrator point of view, it has allowed understanding of process capabilities for design as well as assessing manufacturing variability. The maps have allowed supply chain participants to use diagnostics and develop efficient and reliable processes improving their product yields. Non-dimensionalized maps also enable transparent interaction between designers and manufacturers without compromising proprietary information.

- The advanced coating mechanics detailed in the third case study is now being adopted across the enterprise as it is enabling more rapid introduction manufacturing process improvement and also evaluation of new materials compositions and powder sources. Conversations are now underway at system integrators to develop new methodologies for design and manufacturing evaluation.

\section{Part 4: Path forward: integration data, models and industrial experiences}

The PAINT case studies mentioned in the above section demonstrate the innovation agenda for thermal spray. It approaches the problem in a multi-tiered manner. Fusion of models and experiments allows for knowledge guided development of advanced materials and manufacturing technologies which not only has the benefit of immediacy of impact, but also enable robust and sustained expansion of the knowledge-technology portfolio. By seeking association during early stage with system designers, scientists and innovators have an opportunity to benchmark their advance concepts with contemporary knowledge and more importantly system needs. Concurrently, the partnership provides OEMs to rapidly adapt new knowledge and also guide the innovation process. 
Continuous assessment of the value proposition of the innovation allows both parties to develop realistic assessment of needs and developments ensuring a motif for sustained knowledge and technology creation and a more efficient translation of the innovation.

The case studies presented here are predominantly experimentally driven with limited guidance available through models. In large part this is attributed to the nature of the technology/application as a lack of fundamental material data used in these extreme environments. Applications have far outpaced developments and as such needs for advanced models or diagnostics have not been perceived to be of importance. However, the situation is changing: future applications of coatings are much more stringent:

- As engine operation temperatures have steadily increased the role of TBCs has moved from life extension to prime-reliant, the latter requiring incorporation into design and stringent requirement of durability and reliability.

- Damage tolerant coatings now require consideration of the effects of coating design and its manufacturing on the substrate material itself. (e.g. fatigue and corrosion behavior of the coated system).

- As the portfolio of materials expands into the arena of functional systems (electronics, sensors, fuel cells), the interplay between process, performance and applications far more complex, one that cannot be optimized through the past Edisonian development strategies.

In all of these situations, it is clear that availability of apriori knowledge, databases and models will significantly reduce the development time, reduce overall cost as well as enhance the output of activity in terms of efficient, robust and reliable manufacturing processes. Thus, future developments will/should involve more pervasive use of models for virtual experimentation. Secondly integration of models with experiments and development of relevant databases will be crucial. The latter not only involves generally available material properties but those that are defined by a manufactured "state". In the next section, some examples of such developments as an evolution of the case studies are presented.

\section{Model guided of spray hardware and process parameters}

The injection sweet-spot optimization presented in the first case study, although comprehensive, was conducted for just one or two materials (alumina and zirconia) and a few process hardware configurations (external injection plasma spray). Given the numerous variants of plasma spray devices and multitude of feedstock characteristics (powder type, manufacturing method, particle size distribution etc.) an exhaustive assessment of the material/process combination for even this simplest of processes, assessment can be expensive and time consuming. In this situation, application of models both from the point of experimental guidance as well as from the point of new hardware or feedstock materials design is highly beneficial.

In one example, the LAVA-3DP plasma spray simulation model was applied to determine the role of powder injector angle onto the plasma spray torch. As shown in Figure 18, injectors can be positioned in multiple ways so as to introduce the powders inward towards the nozzle, at 90 degrees (as tested in the first case study) or downward away from the 
(a)

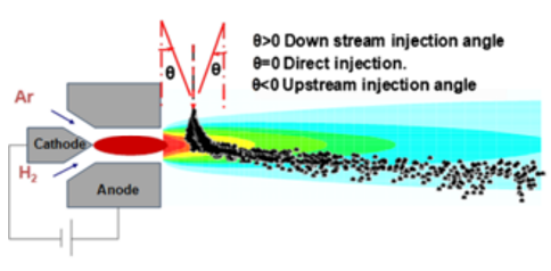

(b)

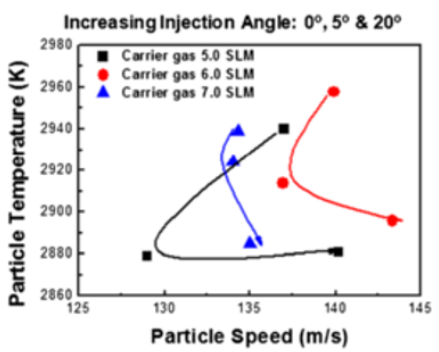

Figure 18 Model based assessment of changes in process hardware. (a) A schematic of one of the possible hardware modification (powder injection angle) capable of changing the particle state in the plasma plume (b) particles $T$ and $V$ values obtained from the model reflecting the effect of change in injection angle coupled with carrier gas flow rate [59].

nozzle [59]. For each of these situations, the particle-plasma coupling can be substantially different including the behavior of different particle sizes within a standard powder distribution. The simulation allowed for rapid assessment of many experimental scenarios and is plotted as a particle temperature-velocity diagram. The results of the simulation show the trends in terms of the energy coupling from plasma to particle and allows for scanning through a very large process parameter space (for these 3 injector conditions, several plasma parameters were varied in the model). Such studies in conjunction with key validation experiments can be incorporated within an ICME framework. The outcome of such an ICME capability will allow for new spray device development as well as accelerated optimization of new materials and their powder variants.

\section{Synthesis of virtual process maps}

The evolution of the LAVA-3DP modeling capability for plasma spray also enables virtual process developments for instance simulated process maps. An example of such a map is shown in Figure 19 along with its experimentally determined counterpart. The results

(a)

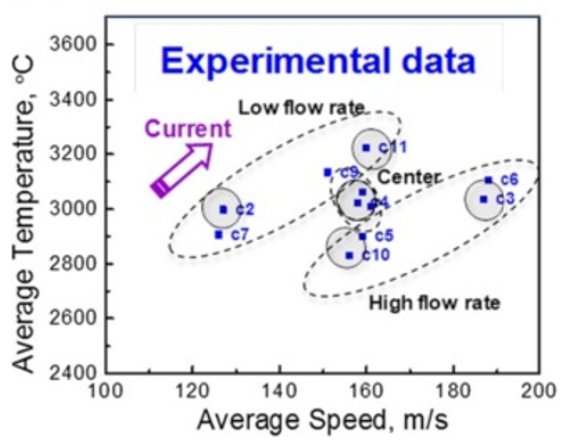

(b)

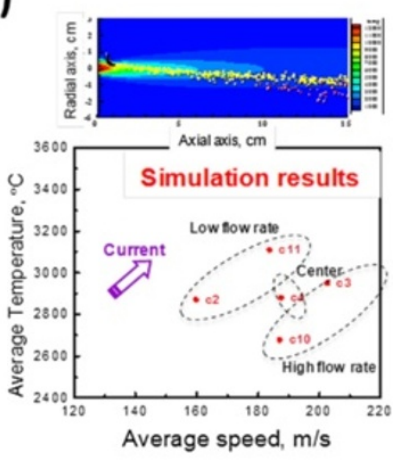

Figure 19 Comparison of experimental and simulated process maps for plasma spraying of yttria stabilized zirconia (YSZ) [31]. (a) $T$ and $V$ map constructed from the experimental results of ten different processing conditions (b) the average $T$ and $V$ values obtained from modeling of five selected processing condition corresponding to circled area in (a). In both cases particle properties were obtained from measurements or simulation based on 5,000 particles and averaged for each condition. The model is able to capture the overall trends with reasonable accuracy. 
demonstrate the capability of the model not only in capturing trends but also providing predictive capabilities. Additional embodiments of the model include detailed analysis particle temperature distributions, phase content etc. In addition, the model tracks the thermal and kinetic history each particle from injection to the impact location. As such, one can rigorously study the operative mechanisms in energy transfer in a material specific manner. Critical physical phenomena such as oxidation, evaporation, decomposition etc. are captured in the simulation which is hitherto unavailable for experimental determination. Here again, the fusion of model derived knowledge and experimentally validated/adjusted outcomes can be combined within an ICME framework. Such integrated maps can be of great value to both academia and industry in accelerated insertion of new materials and process concepts. Future modeling tools will invariably need to incorporate supersonic combustions spray and non-thermal spray processes such as cold spray. There are scattered efforts around the world in these developments but will require integration and validation.

\section{Mechanics of coating formation, insitu curvature simulation}

The use of beam curvature technique and its utilization for industrial process optimization and control has been experimentally demonstrated in the earlier section. Although much has been learned from experimental analysis, the deposit formation dynamics and stress generation remain a highly complex phenomenon for full mechanical description. In recent years, Nakamura et al. have developed advanced numerical scheme to model the deposition formation dynamics in the context of in situ beam curvature monitoring as described earlier [70]. Figure 20 shows the model and an illustrative comparison of the experiment and simulation results. The simulation with appropriate input of physical phenomena (e.g. thermal gradient, deposition flux) is also able to provide layer-by-layer evolution of curvature and contributing factors (stress, stiffness). Although much remains to be done in terms of capturing second order effects in the simulation (relaxation mechanisms, porosity, cracking etc.) the model can provide guidance to experiments and allow for assurance of data interpretation.

\section{Optimization of non-linear properties}

Earlier in section on non-linear models for coatings mechanical properties, it was shown that the anelastic parameters uniquely describe the non-linear properties of a plasma sprayed ceramic. The quantification of these parameters provides a platform Figure 15c to compare coatings fabricated with various processing parameters, spray hardware and

(a)

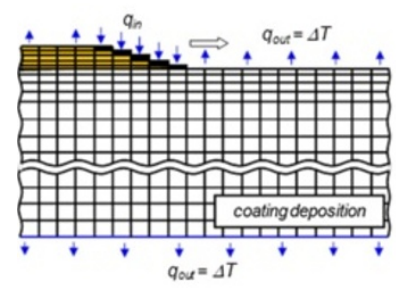

(b)

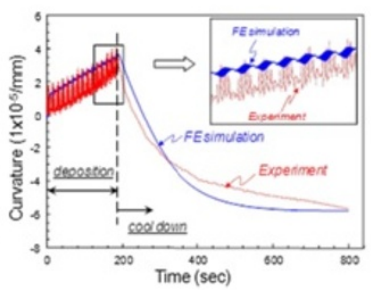

(c)

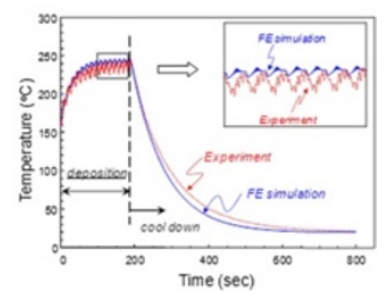

Figure 20 Finite element simulation of the beam curvature evolution during thermal spray [70]. (a) Model built by assembly discrete "bricks" of materials to effectively capture the experimental observations both for (b) curvature evolution and (c) temperature description. Excellent agreement between model and experiment is noted allowing for model guided interpretation and experimental design. 
materials, temporal and spatial variability, which enabled guidelines for a property based design of coatings. Of particular interest is the role of interlamellar sliding mechanisms that contribute to the thermal/mechanical cycle hysteresis [75]. To aid in its understanding, Nakamura et al. developed a multi crack 2D analytical model as well as 3D numerical model to understand and simulate the effect of coating defects' and interface frictional characteristics on its anelastic behavior of spray formed ceramics. The model suggested that interface separation and friction are key factors that define the hysteresis. At small interface separations and low interface sliding friction parameters the hysteresis is absent or negligible. At the same time, at large interface separation there is limited contact between the interfaces, thus contributing to no frictional dissipation. The maximum hysteresis is observed at a friction coefficient of 0.5 and moderate crack opening dimensions. Experimental results through deliberate modifications to interface character (e.g. smooth amorphous interfaces rather than rough crystalline interfaces) [76] confirm the model derived results suggesting that that physical mechanisms can be incorporated to advanced compliant coating design based on novel mechanisms. Our current PAINT efforts are aimed at industrial design of coatings with controlled introduction of anelasticity [76].

\section{Establishing framework for a fully integrated ICME}

The fusion of design input, materials data, process maps/models and in line diagnostics will ultimately enable development of ICME schemes. The overall ICME framework for thermal spray technology is illustratively captured in Figure 21. The integration involves five component elements (Performance driven design, structure property relations, process-structure relations, process property relations and process-materials interactions). For complex engineering systems, design, materials and manufacturing requirements are invariably performance driven and as such embody the development and transition. However, ICME will require many sub-processes and validation schemes which are captured through inter relationships among the component elements).

Figure 21 has been constructed from the point of view of new TBC development, an enabling developmental activity within the turbine engine community. Emerging performance drivers include higher engine operational temperature and resistance to ash attack both of which are limited with the current bill of materials (e.g. Yttria stabilized zirconia). Zirconia coatings do not resist ash particle attack and are also susceptible to accelerated sintering and phase instability at temperatures $>1200 \mathrm{C}$. One material system under consideration is rare-earth zirconates, mainly Gadolinium Zirconate $\left(\mathrm{Gd}_{2} \mathrm{Zr}_{2} \mathrm{O}_{7}\right)$. Working apriori through the ICME framework will allow concurrent consideration of performance, property and process enablers and their interaction. Work is underway specifically in this area addressed through the PAINT framework and paying rich dividends in terms of both innovation adoption and integration.

\section{Process property linkages enabling coating design and optimization}

The fusion of process and materials property data through the use of maps and property monitoring will ultimately enable consideration of ICME schemes. One example of such a scheme is outlined in Figure 22. In this ICME subsystem, the integration is primarily assembled from parametric design and experimental data but one that seeks to connect all aspects of the sub-processes and materials input. This initial scheme can be enhanced and used through models and simulations so as to expand the portfolio of 


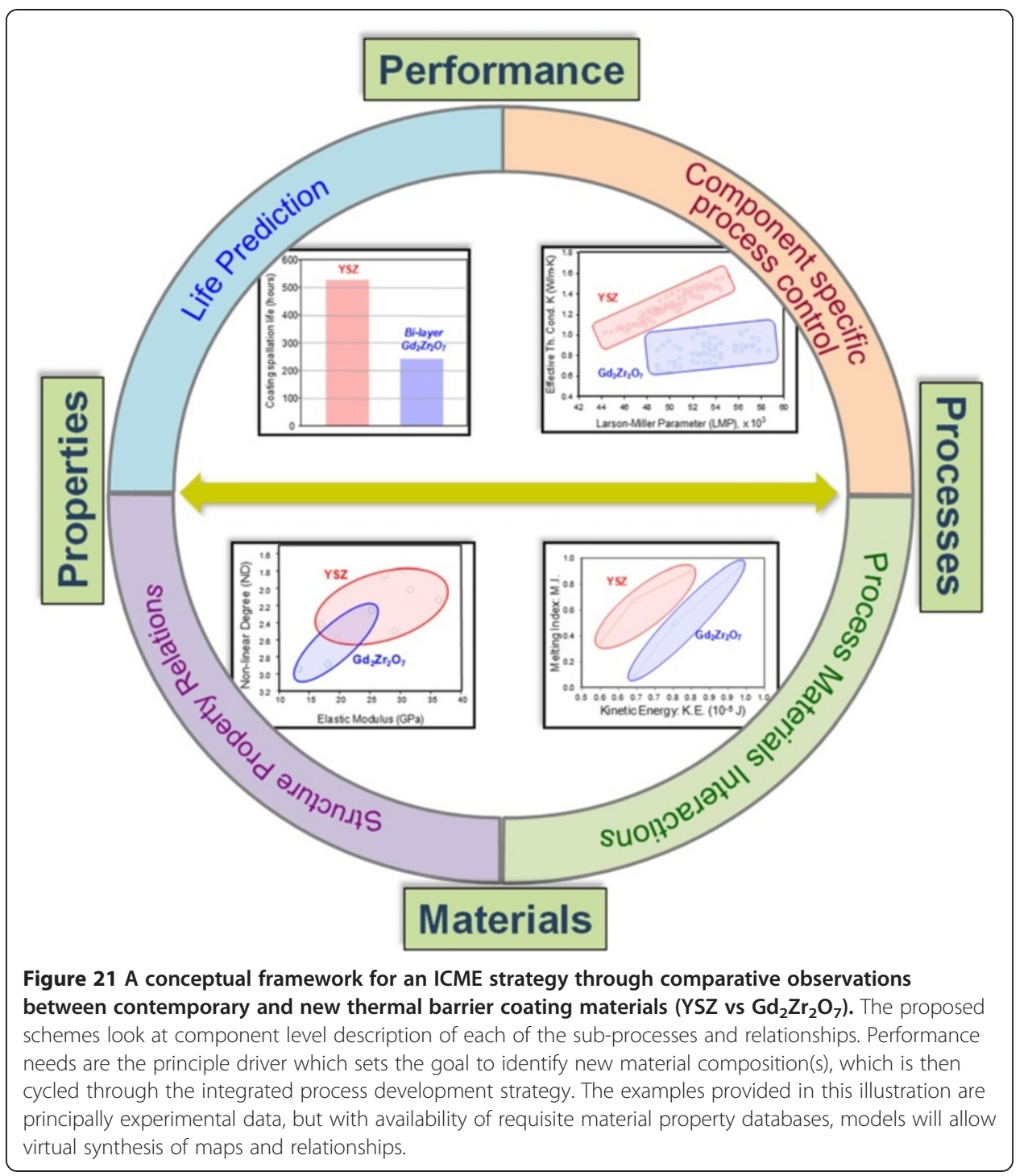

materials and processes. Industry is already using such regression schemes in their process and manufacturing development/optimization programs and thus can incorporate the added insights resulting from scientific knowledge and data. Thermal spray represents an excellent vehicle to pilot such concepts and is currently being explored within the Stony Brook's Consortium program.

\section{Part 5: summary and conclusions}

This review presents a discussion on the challenges and opportunities with respect to accelerating incorporation of advanced knowledge and technologies into industrial practice of materials and manufacturing. A new framework PAINT is presented that strives to bring system developers and supply chain together facilitated through an academic intermediary with the specific goal to accelerate communication among players and concurrently establish a methodology for robust assessment of advanced technologies, knowledge and models in promoting materials and manufacturing innovation. 


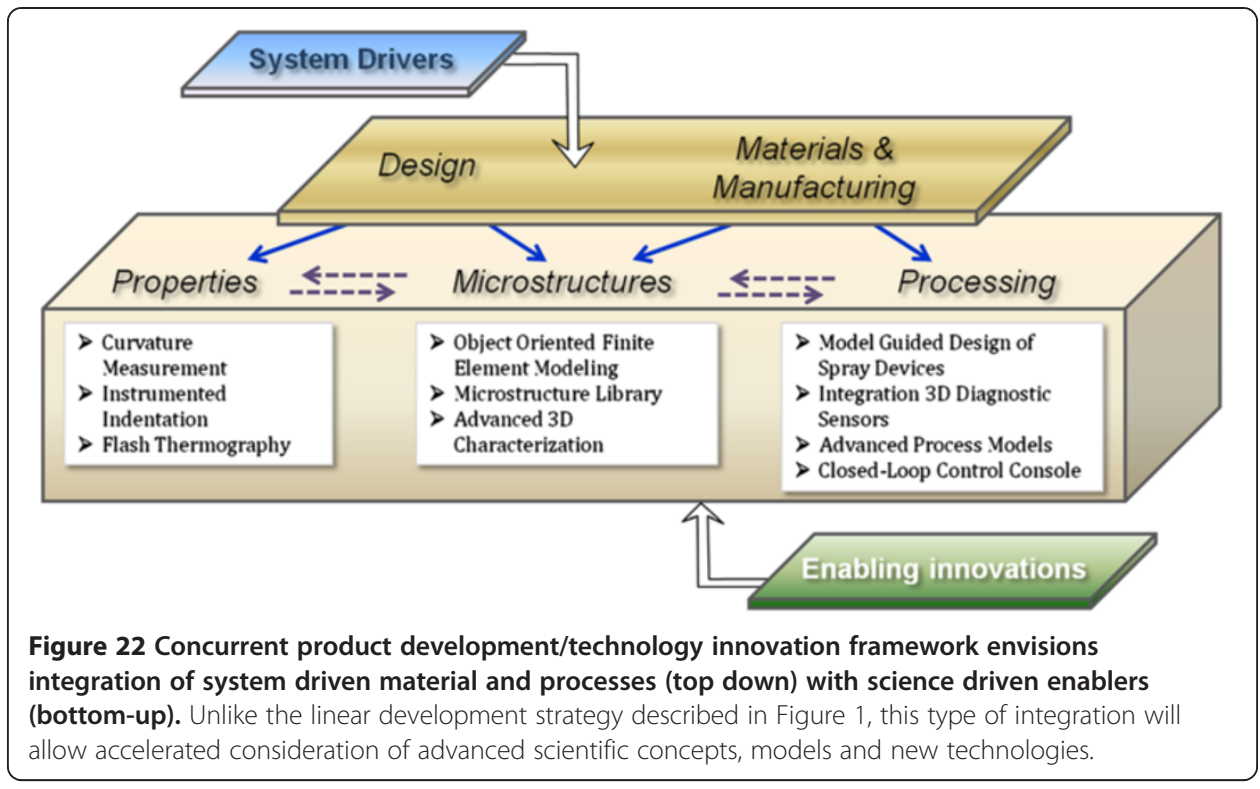

Thermal spray, a platform of materials and manufacturing technology is used as a vehicle to describe constituent science and technology elements along with identification of the critical components needed for integrating materials and manufacturing innovation. The key ingredients of success include both system level appreciations of the requirements as well as a demonstration of the value proposition of the innovation. Given that each stakeholder has a different perspective on needs and outcomes, successful transition of new knowledge and technologies and its accelerated adoption require effective partnerships among system designers, innovators and knowledge enhancers. These partnerships take time and trust to build and sustain and made possible through effective communication among the stake holders.

For accelerated insertion of new technology and knowledge an intersection of the system and innovation pathways described in Figure 1 need to be achieved in a timely manner along with appropriate "stage-gates" to outline the needs and assess the values of innovative technologies [77]. For the specific example of thermal spray technology, such a framework is presented in Figure 22 connecting the system needs with enabling innovation. Through the use of case studies, this paper demonstrates these connections and points a pathway for exploitation of such partnership concepts in other areas of materials and manufacturing.

Although the case studies presented here are specific to the field of thermal spray, but the methodologies are extendable to other materials and manufacturing systems. This is likely to be critical for the emerging ICME framework, where input to develop appropriate models and experiments as well as integration will no doubt require a partnership among the key stakeholders. PAINT concepts demonstrated in this paper such as consortia, field trips and even industrial validation of advanced models/experiments will greatly enhance both successful transition and reduced time. In essence PAINT attempts to bridge scientific advancements and disruptive concepts with industrial system roads maps to accelerate implementation of innovation. Templating these integration and PAINT concepts across different market segments will be key to securing the innovation agenda in advanced materials and manufacturing. 


\section{Competing interests}

This review article integrates information from several past publications on the scientific case studies as such no competing interests exist. BC and SS are currently in the process of developing advanced hardware and software based on some of the instrumentation and modeling concepts presented in this paper for their consideration in industrial process control.

\section{Authors' contributions}

SS designed and integrated the manuscript and was responsible for majority of the written sections. GD developed the integrated figures and contributed to the section on non-linear properties. AV contributed to the section of particle peening stress and in situ monitoring of coating dynamics. BC contributed to particle injection description and knowledge transfer partnerships via field trips compiling Table 1. All authors read and approved the final manuscript.

\section{Acknowledgements}

The research case studies presented in this paper has been developed over many years of support from the National Science Foundation through the Materials Research Science and Engineering Center as well as the Grant Opportunities for Academic liaisons with industry program. The sustained support for enabling partnership through the members of the Consortium for Thermal Spray Technology is gratefully acknowledged. The motivation for this paper was stimulated in part by the recently awarded Partnership for Innovation grant from the Industrial Innovation and Partnerships division of the Nationals Science Foundation under award IIP 1114205. This NSF award focuses not only on science but also engagement of science for innovation. The authors are grateful to Dr. Chris Weyant for assisting with laying out Figure 1 of this paper and many fruitful discussions during the inception of the PAINT idea.

\section{Author details}

${ }^{1}$ Center for Thermal Spray Research, Stony Brook University, Stony Brook, NY 11794-2275, USA. ${ }^{2}$ Current address: Universidad San Francisco de Quito, Quito, Ecuador. ${ }^{3}$ Current addresse: ReliaCoat Technologies, LLC, Setauket, NY, USA.

\section{Received: 11 February 2013 Accepted: 29 March 2013}

Published: 26 April 2013

\section{References}

1. Moore GA (2002) Crossing the Chasm: Marketing and Selling Disruptive Products to Mainstream Customers. HarperCollins, NY

2. Herman H, Sampath S, McCune R (2000) Thermal spray: Current status and future trends. MRS Bull 25:17-25

3. Sampath S (2010) Thermal Spray Applications in Electronics and Sensors: Past, Present, and Future. J Therm Spray Techn 19:921-949

4. Stover D, Hathiramani D, Vassen R, Damani RJ (2006) Plasma-sprayed components for SOFC applications. Surf Coat Tech 201:2002-2005

5. Gitzhofer F, Boulos M, Heberlein J, Henne R, Ishigaki T, Yoshida T (2000) Integrated fabrication processes for solidoxide fuel cells using thermal plasma spray technology. MRS Bull 25:38-42

6. Fauchais P (2004) Understanding plasma spraying. J Phys D Appl Phys 37:R86-R108

7. Kuroda S, Clyne TW (1991) The quenching stress in thermally sprayed coatings. Thin Solid Films 200:49-66

8. Moreau CML, Cielo P (1991) Method and apparatus for monitoring the temperature and velocity of plasma sprayed particles. US Patent 5:180-921

9. Vassen R, Traeger F, Stover D (2004) Correlation between spraying conditions and microcrack density and their influence on thermal cycling life of thermal barrier coatings. J Therm Spray Techn 13:396-404

10. Moreau C, Cielo P, Lamontagne M, Dallaire S, Vardelle M (1990) Impacting Particle Temperature Monitoring during Plasma Spray Deposition. Meas Sci Technol 1:807-814

11. Vassen R, Stuke A, Stover D (2009) Recent Developments in the Field of Thermal Barrier Coatings. J Therm Spray Techn 18:181-186

12. Fauchais P, Vardelle A (2000) Heat, mass and momentum transfer in coating formation by plasma spraying. Int J Therm Sci 39:852-870

13. Fukumoto M, Shiiba M, Kaji H, Yasui T (2005) Three-dimensional transition map of flattening behavior in the thermal spray process. Pure Appl Chem 77:429-442

14. Pfender E (1999) Thermal plasma technology: Where do we stand and where are we going? Plasma Chem Plasma P 19:1-31

15. Duan Z, Heberlein J (2002) Arc instabilities in a plasma spray torch. J Therm Spray Techn 11:44-51

16. Dykhuizen RC (1994) Review of Impact and Solidification of Molten Thermal Spray Droplets. J Therm Spray Techn 3:351-361

17. Mostaghimi J, Chandra S, Ghafouri-Azar R, Dolatabadi A (2003) Modeling thermal spray coating processes: a powerful tool in design and optimization. Surf Coat Tech 163:1-11

18. Bussmann M, Chandra S, Mostaghimi J (2000) Modeling the splash of a droplet impacting a solid surface. Phys Fluids 12:3121-3132

19. Ghafouri-Azar R, Mostaghimi J, Chandra S, Charmchi M (2003) A stochastic model to simulate the formation of a thermal spray coating. J Therm Spray Techn 12:53-69

20. Pasandideh-Fard M, Chandra S, Mostaghimi J (2002) A three-dimensional model of droplet impact and solidification. Int J Heat Mass Tran 45:2229-2242

21. Pasandideh-Fard M, Pershin V, Chandra S, Mostaghimi J (2002) Splat shapes in a thermal spray coating process: Simulations and experiments. J Therm Spray Techn 11:206-217

22. Fincke JR, Haggard DC, Swank WD (2001) Particle temperature measurement in the thermal spray process. J Therm Spray Techn 10:255-266 
23. Zhang H (1999) Theoretical analysis of spreading and solidification of molten droplet during thermal spray deposition. Int J Heat Mass Tran 42:2499-2508

24. Wan YP, Prasad V, Wang GX, Sampath S, Fincke JR (1999) Model and powder particle heating, melting, resolidification, and evaporation in plasma spraying processes. J Heat Trans-T Asme 121:691-699

25. Berghaus JO, Marple B, Moreau C (2006) Suspension plasma spraying of nanostructured WC-12Co coatings. J Therm Spray Techn 15:676-681

26. Ravi BG, Sampath S, Gambino R, Devi PS, Parise JB (2006) Plasma spray synthesis from precursors: Progress, issues, and considerations. J Therm Spray Techn 15:701-707

27. Vassen R, Kassner H, Mauer G, Stover D (2010) Suspension Plasma Spraying: Process Characteristics and Applications. J Therm Spray Techn 19:219-225

28. Padture NP, Schlichting KW, Bhatia T, Ozturk A, Cetegen B, Jordan EH, Gell M, Jiang S, Xiao TD, Strutt PR, Garcia E, Miranzo P, Osendi MI (2001) Towards durable thermal barrier coatings with novel microstructures deposited by solution-precursor plasma spray. Acta Mater 49:2251-2257

29. Toma FL, Bertrand G, Klein D, Coddet C, Meunier C (2006) Nanostructured photocatalytic titania coatings formed by suspension plasma spraying. J Therm Spray Techn 15:587-592

30. Killinger A, Gadow R, Mauer G, Guignard A, Vassen R, Stover D (2011) Review of New Developments in Suspension and Solution Precursor Thermal Spray Processes. J Therm Spray Techn 20:677-695

31. Colmenares-Angulo J, Shinoda K, Wentz T, Zhang W, Tan Y, Sampath S (2011) On the Response of Different Particle State Sensors to Deliberate Process Variations. J Therm Spray Techn 20:1035-1048

32. Mauer G, Vassen R, Stover D, Kirner S, Marques JL, Zimmermann S, Forster G, Schein J (2011) Improving Powder Injection in Plasma Spraying by Optical Diagnostics of the Plasma and Particle Characterization. J Therm Spray Techn 20:3-11

33. Streibl T, Vaidya A, Friis M, Srinivasan V, Sampath S (2006) A critical assessment of particle temperature distributions during plasma spraying: Experimental results for YSZ. Plasma Chem Plasma P 26:73-102

34. Wang XY, Zhang H, Zheng LL, Sampath S (2002) An integrated model for interaction between melt flow and non-equilibrium solidification in thermal spraying. Int J Heat Mass Tran 45:2289-2301

35. Wan YP, Fincke JR, Sampath S, Prasad V, Herman H (2002) Modeling and experimental observation of evaporation from oxidizing molybdenum particles entrained in a thermal plasma jet. Int J Heat Mass Tran 45:1007-1015

36. Xiong HB, Zheng LL, Sampath S, Williamson RL, Fincke JR (2004) Three-dimensional simulation of plasma spray: effects of carrier gas flow and particle injection on plasma jet and entrained particle behavior. Int J Heat Mass Tran 47:5189-5200

37. Vaidya A, Sirinivasan V, Streibl T, Friis M, Chi W, Sampath S (2008) Process maps for plasma spraying of yttria-stabilized zirconia: An integrated approach to design, optimization and reliability. Mat Sci Eng a-Struct 497:239-253

38. Zhang W, Sampath S (2009) A Universal Method for Representation of In-Flight Particle Characteristics in Thermal Spray Processes. J Therm Spray Techn 18:23-34

39. Fauchais P, Fukumoto M, Vardelle A, Vardelle M (2004) Knowledge concerning splat formation: An invited review. J Therm Spray Techn 13:337-360

40. Jiang XY, Sampath S, Herman H (2001) Grain morphology of molybdenum splats plasma-sprayed on glass substrates. Mat Sci Eng a-Struct 299:235-240

41. Jiang XY, Wan YP, Herman H, Sampath S (2001) Role of condensates and adsorbates on substrate surface on fragmentation of impinging molten droplets during thermal spray. Thin Solid Films 385:132-141

42. Zhang H, Wang XY, Zheng LL, Sampath S (2004) Numerical simulation of nucleation, solidification, and microstructure formation in thermal spraying. Int J Heat Mass Tran 47:2191-2203

43. Fukumoto M, Yamaguchi T, Yamada M, Yasui T (2007) Splash splat to disk splat transition behavior in plasmasprayed metallic materials. J Therm Spray Techn 16:905-912

44. Wan YP, Zhang H, Jiang XY, Sampath S, Prasad V (2001) Role of solidification, substrate temperature and Reynolds number on droplet spreading in thermal spray deposition: Measurements and modeling. J Heat Trans-T Asme 123:382-389

45. Zhang W, Wei GH, Zhang H, Zheng LL, Welch DO, Sampath S (2007) Toward the achievement of substrate melting and controlled solidification in thermal spraying. Plasma Chem Plasma P 27:717-736

46. Kulkarni A, Sampath S, Goland A, Herman H, Dowd B (2000) Computed microtomography studies to characterize microstructure-property correlations in thermal sprayed alumina deposits. Scripta Mater 43:471-476

47. Kulkarni A, Wang Z, Nakamura T, Sampath S, Goland A, Herman H, Allen J, llavsky J, Long G, Frahm J, Steinbrech RW (2003) Comprehensive microstructural characterization and predictive property modeling of plasma-sprayed zirconia coatings. Acta Mater 51:2457-2475

48. Nakamura T, Wang T, Sampath S (2000) Determination of properties of graded materials by inverse analysis and instrumented indentation. Acta Mater 48:4293-4306

49. Tan Y, Longtin JP, Sampath S (2006) Modeling thermal conductivity of thermal spray coatings: Comparing predictions to experiments. J Therm Spray Techn 15:545-552

50. Chi WG, Sampath S, Wang H (2008) Microstructure-thermal conductivity relationships for plasma-sprayed yttriastabilized zirconia coatings. J Am Ceramic Soc 91:2636-2645

51. Tan Y, Shyam A, Choi WB, Lara-Curzio E, Sampath S (2010) Anisotropic elastic properties of thermal spray coatings determined via resonant ultrasound spectroscopy. Acta Mater 58:5305-5315

52. Tan Y, Longtin JP, Sampath S, Wang H (2009) Effect of the Starting Microstructure on the Thermal Properties of As-Sprayed and Thermally Exposed Plasma-Sprayed YSZ Coatings. J Am Ceramic Soc 92:710-716

53. Sharma A, Gouldstone A, Sampath S, Gambino RJ (2006) Anisotropic electrical conduction from heterogeneous oxidation states in plasma sprayed TiO2 coatings. J Appl Phys 100:114906-114909

54. Sampath S, Jiang X (2001) Splat formation and microstructure development during plasma spraying: deposition temperature effects. Mat Sci Eng a-Struct 304:144-150

55. Shinoda K, Liang SS, Sampath S, Gambino RJ (2011) Processing effects on in-flight particle state and functional coating properties of plasma-sprayed manganese zinc ferrite. Mater Sci Eng B-Adv 176:22-31 
56. Sampath S, Jiang XY, Matejicek J, Prchlik L, Kulkarni A, Vaidya A (2004) Role of thermal spray processing method on the microstructure, residual stress and properties of coatings: an integrated study for Ni-5 wt.\%Al bond coats. Mat Sci Eng a-Struct 364:216-231

57. Srinivasan V, Friis M, Vaidya A, Streibl T, Sampath S (2007) Particle injection in direct current air plasma spray: Salient observations and optimization strategies. Plasma Chem Plasma P 27:609-623

58. Vardelle M, Vardelle A, Fauchais P, Li Kl, Dussoubs B, Themelis NJ (2001) Controlling particle injection in plasma spraying. J Therm Spray Techn 10:267-284

59. Zhang W, Zheng LL, Zhang H, Sampath S (2007) Study of injection angle and carrier gas flow rate effects on particles in-flight characteristics in plasma spray process: Modeling and experiments. Plasma Chem Plasma P 27:701-716

60. Dwivedi G, Wentz T, Sampath S, Nakamura T (2010) Assessing Process and Coating Reliability Through Monitoring of Process and Design Relevant Coating Properties. J Therm Spray Techn 19:695-712

61. Valarezo A, Sampath S (2011) An Integrated Assessment of Process-Microstructure-Property Relationships for Thermal-Sprayed NiCr Coatings. J Therm Spray Techn 20:1244-1258

62. Sampath S, Srinivasan V, Valarezo A, Vaidya A, Streibl T (2009) Sensing, Control, and In Situ Measurement of Coating Properties: An Integrated Approach Toward Establishing Process-Property Correlations. J Therm Spray Techn 18:243-255

63. Williamson RL, Fincke JR, Chang CH (2000) A computational examination of the sources of statistical variance in particle parameters during thermal plasma spraying. Plasma Chem Plasma P 20:299-324

64. Stoney GG (1909) The tension of metallic films deposited by electrolysis. Proc R Soc Lond Ser Math Phys Character 82:172-175

65. Brenner A, Senderoff S (1949) Calculation of Stress in Electrodeposits from the Curvature of a Plated Strip. J Res Natl Bur Stand 42:105-123

66. Kesler O, Finot M, Suresh S, Sampath S (1997) Determination of processing-induced stresses and properties of layered and graded coatings: Experimental method and results for plasma-sprayed Ni-Al2O3. Acta Mater 45:3123-3134

67. Matejicek J, Sampath S (2003) In situ measurement of residual stresses and elastic moduli in thermal sprayed coatings - Part 1: apparatus and analysis. Acta Mater 51:863-872

68. Matejicek J, Sampath S, Gilmore D, Neiser R (2003) In situ measurement of residual stresses and elastic moduli in thermal sprayed coatings - Part 2: processing effects on properties of Mo coatings. Acta Mater 51:873-885

69. Tsui YC, Clyne TW (1997) An analytical model for predicting residual stresses in progressively deposited coatings.1. Planar geometry. Thin Solid Films 306:23-33

70. Nakamura T, Liu YJ (2007) Determination of nonlinear properties of thermal sprayed ceramic coatings via inverse analysis. Int J Solids Struct 44:1990-2009

71. Kuroda S, Tashiro Y, Yumoto H, Taira S, Fukanuma H (1998) Peening action and residual stresses in HVOF thermal spraying of 316L stainless steel. 15th Int Therm Spray Conf 1:569-574

72. Kuroda S, Tashiro Y, Yumoto H, Taira S, Fukanuma H, Tobe S (2001) Peening action and residual stresses in highvelocity oxygen fuel thermal spraying of 316L stainless steel. J Therm Spray Techn 10:367-374

73. Valarezo A, Choi WB, Chi W, Gouldstone A, Sampath S (2010) Process Control and Characterization of NiCr Coatings by HVOF-DJ2700 System: A Process Map Approach. J Therm Spray Techn 19:852-865

74. Liu Y, Nakamura T, Srinivasan V, Vaidya A, Gouldstone A, Sampath S (2007) Non-linear elastic properties of plasmasprayed zirconia coatings and associated relationships with processing conditions. Acta Mater 55:4667-4678

75. Liu YJ, Nakamura T, Dwivedi G, Valarezo A, Sampath S (2008) Anelastic Behavior of Plasma-Sprayed Zirconia Coatings. J Am Ceram Soc 91:4036-4043

76. Dwivedi G, Nakamura T, Sampath S (2011) Controlled Introduction of Anelasticity in Plasma-Sprayed Ceramics. J Am Ceram Soc 94:S104-S111

77. Cooper RG, Edgett SJ, Kleinschmidt EJ (2000) New problems, new solutions: making portfolio management more effective. Res Technol Manage 43(2):18-33

doi:10.1186/2193-9772-2-1

Cite this article as: Sampath et al:: Partnership for accelerated insertion of new technology: case study for thermal spray technology. Integrating Materials and Manufacturing Innovation 2013 2:1.

\section{Submit your manuscript to a SpringerOpen ${ }^{\circ}$ journal and benefit from:}

- Convenient online submission

Rigorous peer review

- Immediate publication on acceptance

- Open access: articles freely available online

- High visibility within the field

- Retaining the copyright to your article

Submit your next manuscript at $\boldsymbol{\sim}$ springeropen.com 